\title{
ZnO-ZnS Heterojunctions: A Potential Candidate for Optoelectronics Applications and Mineralization of Endocrine Disruptors in Direct Sunlight
}

\author{
Perumal Devaraji, $^{\dagger}$ Maitri Mapa, ${ }^{\dagger}$ Hasna M. Abdul Hakkeem, ${ }^{\dagger}$ Vediappan Sudhakar, ${ }^{\ddagger}$

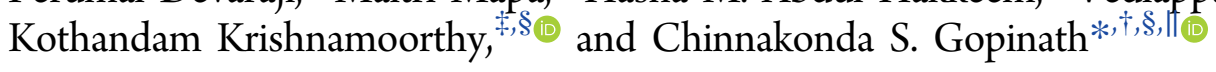 \\ ${ }^{\dagger}$ Catalysis Division, National Chemical Laboratory, Dr Homi Bhabha Road, Pune 411 008, India \\ ${ }^{\ddagger}$ Polymer Science and Engineering Division, ${ }^{\S}$ Network of Institutes for Solar Energy (NISE), and "Center of Excellence on Surface \\ Science, National Chemical Laboratory, Pune 411 008, India
}

Supporting Information

ABSTRACT: Simple solution combustion synthesis was adopted to synthesize $\mathrm{ZnO}-$ $\mathrm{ZnS}(\mathrm{ZS} x)$ nanocomposites using zinc nitrate as an oxidant and a mixture of urea and thiourea as a fuel. A large thiourea/urea ratio leads to more $\mathrm{ZnS}$ in $\mathrm{ZS} x$ with heterojunctions between $\mathrm{ZnS}$ and $\mathrm{ZnO}$ and throughout the bulk; tunable $\mathrm{ZnS}$ crystallite size and textural properties are an added advantage. The amount of $\mathrm{ZnS}$ in $\mathrm{ZS} x$ can be varied by simply changing the thiourea content. Although $\mathrm{ZnO}$ and $\mathrm{ZnS}$ are wide band gap semiconductors, $\mathrm{ZS} x$ exhibits visible light absorption, at least up to $525 \mathrm{~nm}$. This demonstrates an effective reduction of the optical band gap and substantial changes in its electronic structure. Raman spectroscopy, transmission electron microscopy, X-ray photoelectron spectroscopy, and secondary-ion mass spectrometry results show features due to $\mathrm{ZnO}$ and $\mathrm{ZnS}$ and confirm the composite nature with heterojunctions. The above mentioned observations demonstrate the multifunctional nature of $\mathrm{ZS} x$. Bare $\mathrm{ZS} x$ exhibits a promising sunlight-driven

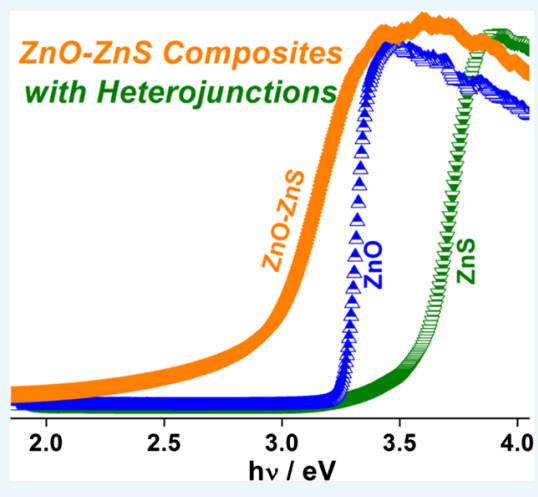
photocatalytic activity for complete mineralization of endocrine disruptors such as 2,4-dichlorophenol and endosulphan. ZSx also exhibits photocurrent generation at no applied bias. Dye-sensitized solar cell performance evaluation with $\mathrm{ZS} x$ shows up to $4 \%$ efficiency and $48 \%$ incident photon conversion efficiency. Heterojunctions observed between $\mathrm{ZnO}$ and $\mathrm{ZnS}$ nanocrystallites in high-resolution transmission electron microscopy suggest the reason for effective separation of electron-hole pairs and their utilization.

\section{INTRODUCTION}

Band gap engineering of wide band gap semiconductor materials is one of the current research areas to harvest maximum visible light absorption ${ }^{1,2 a, b}$ because of its potential applications in clean and renewable energy and pollution abatement. Among various semiconductor oxides, $\mathrm{TiO}_{2}$ and $\mathrm{ZnO}$ are accepted to be the best because of their abundance, chemical stability, nontoxicity, and the efficiency for degradation of hazardous pollutants; the holes produced by photon absorption in these materials exhibit high oxidizing ability. ${ }^{3 a, b, 4}$ Although $\mathrm{TiO}_{2}$ is considered the most important photocatalyst, $\mathrm{ZnO}$ is also a suitable alternative photocatalyst because of its similar band gap energy $(3.37 \mathrm{eV})$, low cost, and higher electronic mobility than $\mathrm{TiO}_{2}{ }^{5,6}$ Moreover, in certain cases, $\mathrm{ZnO}$ has high quantum efficiency and photocatalytic activity than $\mathrm{TiO}_{2} \cdot{ }^{7-9}$ Nonetheless, because of significant photocorrosion, $\mathrm{ZnO}$ has not been explored as thoroughly as $\mathrm{TiO}_{2}$. The common form of Wurtzite $\mathrm{ZnO}$ is a well-known material with a direct band gap of $3.37 \mathrm{eV}$ and employed as a photocatalyst. ${ }^{3}$ In the past few decades, many results have been reported on the synthesis of nanoscale $\mathrm{ZnS}$ crystals because of their special properties. ${ }^{10-13}$ However, $\mathrm{ZnS}$ absorbs only UV light and hence is less attractive for solar light harvesting. Indeed, the $\mathrm{ZnO}-\mathrm{ZnS}(\mathrm{ZS} x)$ core-shell nanostructure has been predicted to exhibit a band gap of $2.07 \mathrm{eV}$. $^{13 \mathrm{~b}}$

Various schemes have been adopted to increase the absorption of visible light, including doping of impurities, sensitization with quantum dots, ${ }^{14}$ and formation of heterostructure semiconductor materials. Doping of anions and/or cations into the $\mathrm{ZnO}$ or $\mathrm{ZnS}$ lattice has been attempted by a number of research groups, ${ }^{15-19}$ and this helps to reach many sophisticated applications, as its electronic structure and properties can be modified significantly. There are many reports on nitride and/or sulphide doping, which can reduce the band gap and lead to visible light absorption in the semiconductor materials. ${ }^{19-23}$ Although nitride is the best candidate for p-type doping in $\mathrm{ZnO}$, there are controversies, such as its not-so-easily reproducible nature, $\mathrm{N}$-content, that still exist. ${ }^{23,24}$ Mapa and Gopinath used simple solution combustion method (SCM) to introduce nitrogen in the $\mathrm{ZnO}$ lattice, but $\mathrm{N} 2 \mathrm{p}$ states were reported to be in the forbidden gap. ${ }^{16}$ Introduction of cations into the lattice

Received: August 12, 2017

Accepted: September 28, 2017

Published: October 16, 2017 


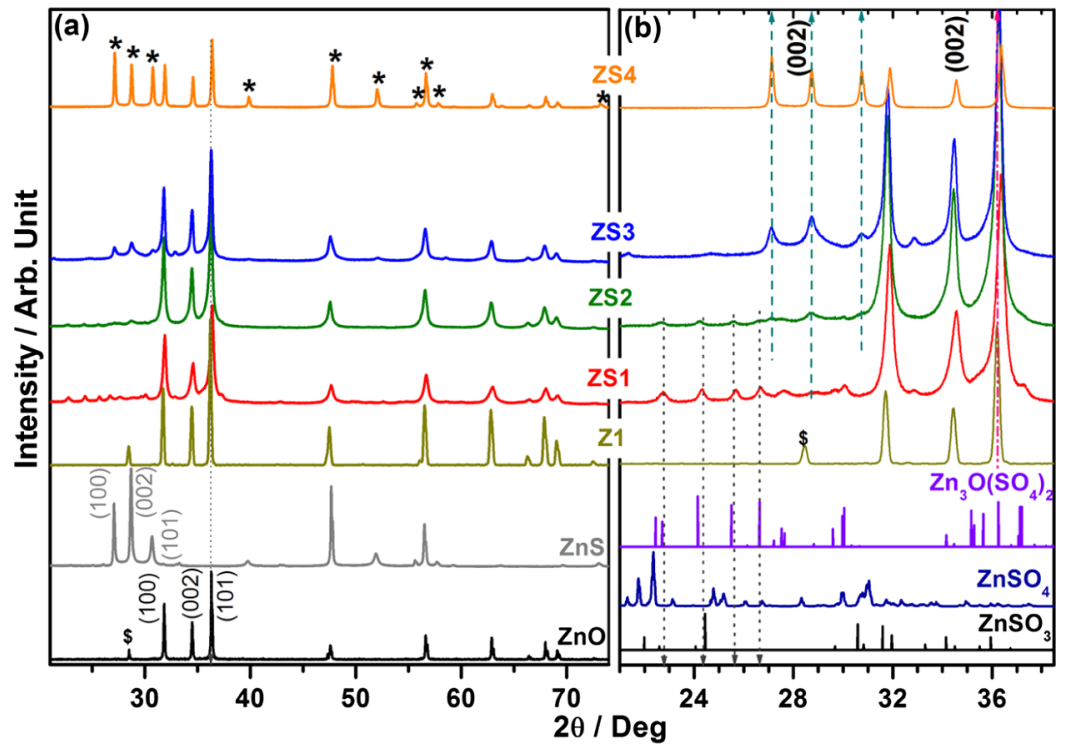

Figure 1. (a) PXRD pattern of $\mathrm{ZS} x$ materials prepared with different ratios of urea, along with $\mathrm{ZnO}$ and $\mathrm{ZnS}$. $\mathrm{Z} 1$ is prepared with urea alone. (b) Enlarged XRD pattern of $\mathrm{ZS} x$ materials for clarity and compared with $\mathrm{Zn}_{3} \mathrm{O}\left(\mathrm{SO}_{4}\right)_{2}, \mathrm{ZnSO}_{4}$ and $\mathrm{ZnSO}_{3}$. A dash-dot line indicates a shift in $\mathrm{ZnO}$ features (101) to a higher angle and a lattice contraction. * and $\$$ indicate $\mathrm{ZnS}$ and Si features, respectively. Dotted and dashed lines are a guide to the eye.

of metal oxide causes thermal instability and invariably introduces mid-gap energy states between the valence band (VB) and the conduction band (CB) which act as recombination centres. $^{25}$ Visible light absorption in the wide band gap semiconductor materials has been developed by solid solution materials. ${ }^{26-30}$ A few groups have studied solid solutions, where a significant improvement in photocatalytic activity was reported with solar light due to red shift in the absorption edge and also modification of textural properties. In 2009, Mapa et al. ${ }^{26}$ prepared $\left(\mathrm{Zn}_{1-z} \mathrm{Ga}_{z}\right)\left(\mathrm{O}_{1-x} \mathrm{~N}_{x}\right)(\mathrm{ZnO}-\mathrm{GaN})$ solid solution by SCM; $\mathrm{ZnO}-\mathrm{GaN}$ exhibits absorption in the visible light region because of formation of solid solution with a band gap reduction. The same group subsequently prepared $\left(\mathrm{Zn}_{1-z} \mathrm{In}_{z}\right)\left(\mathrm{O}_{1-x} \mathrm{~N}_{x}\right)$ $(\mathrm{ZnO}-\mathrm{InN})^{30}$ and $\left(\mathrm{Zn}_{1-z-y} \mathrm{In}_{z} \mathrm{Ga}_{y}\right)\left(\mathrm{O}_{1-x} \mathrm{~N}_{x}\right)(\mathrm{ZnO}-\mathrm{InGaN})^{27}$ solid solutions by adopting the SCM. Later, one was demonstrated to show overall water splitting in the visible light and significant photoconversion efficiency. On similar lines, formation of ZSx was expected to change the electronic structure along with changes in electrical and optical properties; however, the large difference between the ionic sizes of $\mathrm{O}^{2-}$ and $\mathrm{S}^{2-}$ limits the solubility of $\mathrm{ZnS}$ in $\mathrm{ZnO}$ or vice versa, though they belong to the same structure group. ${ }^{31}$ Also, the synthesis of $\mathrm{ZnO}-\mathrm{ZnS}$ heterojunction remains a challenge.

In the present communication, we report on $\mathrm{ZS} x$ composites with heterojunction as an optoelectronic material for photocurrent generation, dye-sensitized solar cells (DSSC), and direct solar light-driven photocatalysis. ZS $x$ was prepared by a simple SCM and without using any template in less than $10 \mathrm{~min}$. It was also demonstrated to show high activity for degradation of endocrine disruptors (ECDs), such as endosulfan (ES) $(6,7,8,9,10,10$-hexachloro-1,5,5a,6,9,9a-hexahydro-6,9 methano 2,4,3-benzo dioxathiepine-3-oxide), 2,4-dichloro phenol (2,4DCP), in direct sun light. The visible light photocatalytic activity under direct sun light has been explained on the basis of the synergetic electronic interaction of wurtzite $\mathrm{ZnO}$ and $\mathrm{ZnS}$ semiconductors as well as the hetreojunctions in $\mathrm{ZS} x$ composites. The present work is a part of ongoing efforts in our laboratories to understand solar energy harvesting/ conversion aspects. $^{32-37}$

\section{RESULTS AND DISCUSSION}

2.1. Structural and Textural Properties. 2.1.1. X-ray Diffraction Studies. The structural aspects of all $\mathrm{ZS} x$ catalysts have been explored by PXRD (powder X-ray diffraction) measurements. Figure $1 \mathrm{a}, \mathrm{b}$ shows a full and enlarged $\left(21-38^{\circ}\right)$ $\mathrm{XRD}$ pattern of the ZSx materials, respectively. Urea/thiourea employed for ZSx preparation varied from 100:0, 75:25, 50:50, and 25:75 to 0:100, and the resulting materials are designated as Z1, ZS1, ZS2, ZS3, and ZS4, respectively. Details of characterization methods are given in $S 1$. It reveals that the as-prepared materials exhibit a hexagonal wurtzite structure and its diffraction pattern changes with the urea/thiourea ratio in the preparation mixture. For the comparison purposes, $\mathrm{XRD}$ patterns of $\mathrm{ZnO}$, $\mathrm{ZnS}$, and $\mathrm{ZnSO}_{4}$ and JCPDS patterns of $\mathrm{ZnSO}_{3}$ and $\mathrm{Zn}_{3} \mathrm{O}\left(\mathrm{SO}_{4}\right)_{2}$ were also included. XRD patterns of pure $\mathrm{ZnO}$ and $\mathrm{ZnS}$ show a hexagonal wurtzite structure, whereas $\mathrm{ZnSO}_{4}$ is of orthorhombic structure, and $\mathrm{Zn}_{3} \mathrm{O}\left(\mathrm{SO}_{4}\right)_{2}$ shows a monoclinic structure. ${ }^{18}$ The $\mathrm{XRD}$ pattern of $\mathrm{Z1}$ is very similar to that of $\mathrm{ZnO}$, except for lattice contraction because of the introduction of $\mathrm{N}$ into the lattice. ${ }^{16}$ The ionic radius of $S^{2-}(1.84 \AA)$ is higher than that of $\mathrm{O}^{2-}(1.4 \AA){ }^{18}$ further, with variation in the ratio of urea to thiourea, average combustion temperature and amount of sulfur introduced also change as well. In the case of ZS1, the urea to thiourea ratio is high at 3 and it leads to complete and fast combustion with high combustion temperature because urea is known to be a good fuel. ${ }^{38}$ Hence, under this combustion condition, a significant amount of sulfur gets oxidized to sulfite, oxy sulfate, and/or sulfate of zinc. A 100\% intense peak for ZS1 was indexed to the hexagonal $\mathrm{ZnO}$ structure with a space group of $\mathrm{P}_{3} \mathrm{mc}$. Low intense peaks observed between $21^{\circ}$ and $31^{\circ}$ (Figure $1 \mathrm{~b}$ ) are attributed to a mixture of oxy sulfate and sulfate of zinc $\left(\mathrm{Zn}_{3} \mathrm{O}\left(\mathrm{SO}_{4}\right)_{2}\right.$ and $\left.\mathrm{ZnSO}_{4}\right)$, with the former dominant on $\mathrm{ZS} 1$. Very broad and low intensity $\mathrm{ZnS}$ features could be seen on $\mathrm{ZS1}$ at $28.7^{\circ}$, corresponding to the (002) facet of $\mathrm{ZnS}{ }^{4}$ indicating the oxidation of surface $\mathrm{ZnS}$ to sulfate-related features (Figure 1b).

In the case of $\mathrm{ZS} 2$, peak intensity for $\mathrm{ZnSO}_{4}, \mathrm{Zn}_{3} \mathrm{O}\left(\mathrm{SO}_{4}\right)_{2}$ was suppressed enormously, and the $\mathrm{ZnS}$ features begin to appear (dashed arrows in Figure $1 \mathrm{~b}$ ). With increasing thiourea content 
in the preparation mixture, the reaction atmosphere changes predominantly toward sulfides along with ammonia. This is partially due to the presence of no oxygen in thiourea compared to urea and hence, enough amount of oxygen was not available for combustion. The lack of oxygen in thiourea does not allow the oxidation of sulfide and significant the $\mathrm{ZnS}$ phase is retained in the product. In other words, the material preparation furnace chamber becomes filled increasingly with in situ-produced reductants, such as $\mathrm{H}_{2} \mathrm{~S}$ and ammonia, with very less oxygen, to interact with nascent $\mathrm{Zn}_{x} \mathrm{O}_{y}$ clusters in a short span of time $(\leq 1 \mathrm{~min})$ under combustion conditions. This is the critical condition which leads to $\mathrm{ZS} x$. Gas product analysis by IR confirms the formation of $\mathrm{H}_{2} \mathrm{~S}$ and $\mathrm{NH}_{3}$. Unlike ZS1 and ZS2, $\mathrm{ZnS}$ and predominant $\mathrm{ZnO}$ features were observed for $\mathrm{ZS} 3$ and without any sulfate feature. Nonetheless, in ZS4, equally strong diffraction features of both $\mathrm{ZnO}$ and $\mathrm{ZnS}$ are found together without any other impurities. Thiourea (100\%) was used as the fuel for ZS4, which is likely the reason for incomplete oxidation of $\mathrm{Zn}_{x} \mathrm{O}_{y}(x / y \approx 2)$ clusters and favors $\mathrm{ZnS}$ formation, under SCM conditions, attesting the successful use of thiourea as a source of S. Sulfide species are not oxidized, which helps to form a large amount of the hexagonal $\mathrm{ZnS}$ wurtzite phase. Therefore, distinct and strong $\mathrm{ZnS}$ features are observed in the XRD pattern along with $\mathrm{ZnO}$. It is reasonable to conclude that a large ionic radius difference between $\mathrm{S}^{2-}(1.84 \AA)$ and $\mathrm{O}^{2-}(1.4 \AA)$ generates the $\mathrm{ZnS}$ phase along with $\mathrm{ZnO}$ in $\mathrm{ZS} 2, \mathrm{ZS} 3$, and $\mathrm{ZS} 4$. It is speculated that the structural similarity of $\mathrm{ZnS}$ and $\mathrm{ZnO}$ helps to form the heterojunctions in a 1:1 ratio; however, this needs careful verification. Not only the diffraction pattern, but also the relative intensity of the diffraction lines of as-prepared materials varied with the changing thiourea content in the reaction mixture. With no or low thiourea content, good crystallinity of $\mathrm{Z1}$ and ZS1 can be observed, as they show very sharp peaks. However, with increasing thiourea content (ZS2) in the preparation mixture, crystallinity of the material decreases, and FWHM of the peaks increases, with the significant peak broadening because of smaller crystallite sizes of $\mathrm{ZnS}$. However, this trend reverses with further increase in the thiourea content, and the crystallite size of $\mathrm{ZnS}$ increases, as shown in Table 1 . Indeed, this observation demonstrates the possibility of fine tuning the $\mathrm{ZnS}$ crystallite size as well as its amount in $\mathrm{ZS} x$. A shift in $\mathrm{ZnO}$ diffraction features to a higher angle from $\mathrm{Z} 1$ to $\mathrm{ZS} 4$ suggests a minor contraction of lattice parameters.

Thermal stability of ZS $x$ was explored with XRD after ex situ calcination of ZS4 and ZS1 at different temperatures for $4 \mathrm{~h}$ in air,

Table 1. Physicochemical Properties of ZSx Materials

$\begin{array}{cccc}\begin{array}{c}\mathrm{ZS} x \text { composition } \\ (\text { code })\end{array} & \begin{array}{c}\mathrm{U} / \mathrm{TU} \text { mole ratio } \\ (\%)^{b}\end{array} & \begin{array}{c}\text { surface area } \\ \left(\mathrm{m}^{2} / \mathrm{g}\right)\end{array} & \begin{array}{c}\mathrm{ZnS} \text { size } \\ (\mathrm{nm})^{c}\end{array} \\ \mathrm{Zn}_{1.04} \mathrm{O}_{0.84} \mathrm{~N}_{0.15}(\mathrm{Z1}) & 100: 0 & 1 & 9 \\ \begin{array}{l}\mathrm{ZnO}_{1.02} \mathrm{~N}_{0.08} \mathrm{~S}_{0.11} \\ (\mathrm{ZS} 1)\end{array} & 75: 25 & 5 & 16 \\ \begin{array}{c}\mathrm{ZnO}_{0.92} \mathrm{~N}_{0.05} \mathrm{~S}_{0.17} \\ (\mathrm{ZS} 2)\end{array} & 50: 50 & 8 & 22 \\ \begin{array}{c}\mathrm{ZnO}_{0.65} \mathrm{~N}_{0.04} \mathrm{~S}_{0.32} \\ (\mathrm{ZS} 3)\end{array} & 25: 75 & 15 & 50(20)^{d} \\ \begin{array}{c}\mathrm{ZnO} \mathrm{n}_{0.51} \mathrm{~N}_{0.04} \mathrm{~S}_{0.47} \\ (\mathrm{ZS} 4)\end{array} & 0: 100 & 20 & \end{array}$

${ }^{a}$ Material composition measured from energy-dispersive X-ray analysis. ${ }^{b}$ The fuel (urea + thiourea) $/ \mathrm{Zn}\left(\mathrm{NO}_{3}\right)_{2}$ molar ratio is maintained as 1 . U/TU (urea/thiourea) percent mole ratio varied is given. ${ }^{c}$ Crystallite size was calculated from the Scherer method. ${ }^{a}$ Crystallite size was measured after calcination at $650{ }^{\circ} \mathrm{C}$. and the results are shown in Figure S1a,b, respectively. No significant change in the intensity of $\mathrm{ZnS}$ and $\mathrm{ZnO}$ features was observed at $\leq 400{ }^{\circ} \mathrm{C}$. However, the intensity of $\mathrm{ZnS}$ peaks decreases, and a simultaneous increase in the intensity of $\mathrm{ZnO}$ features occurs, especially for the materials calcined at $\geq 500{ }^{\circ} \mathrm{C}$. The above mentioned changes are attributed to the systematic oxidation of $\mathrm{ZnS}$ to $\mathrm{ZnO}$ under air atmosphere with an increase in calcination temperature. To have a better understanding of thermal treatment, XRD patterns of ZS4 were recorded in situ at temperatures between 480 and $700{ }^{\circ} \mathrm{C}$, and the results are depicted in Figure 2. Peaks due to $\mathrm{ZnS}(\mathrm{ZnO})$ decrease

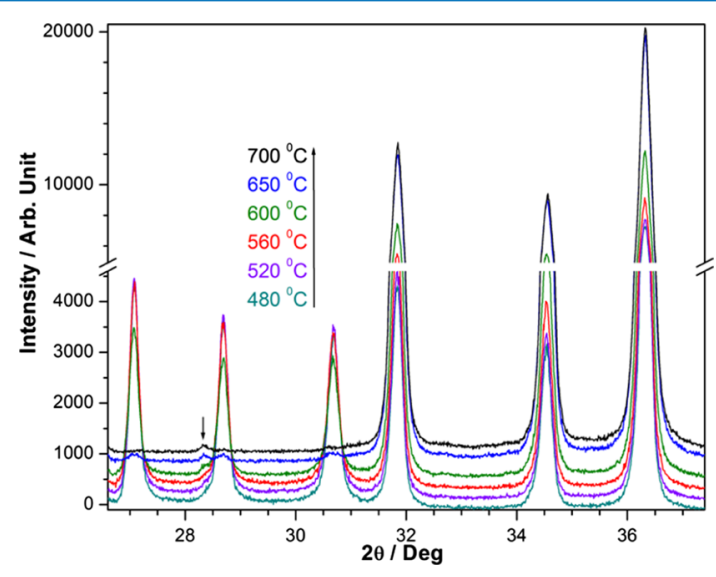

Figure 2. Powder XRD patterns of ZS4 recorded in situ between 480 and $700{ }^{\circ} \mathrm{C}$ show a systematic decrease in the crystallite size of $\mathrm{ZnS}$. An arrow mark indicates the formation of a new phase and it is yet to be identified.

(increases) in intensity as the temperature increases $>480{ }^{\circ} \mathrm{C}$, with the occurrence of a simultaneous broadening (narrowing) demonstrating a reduction (increase) in the crystallite size. Maximum changes in intensity and peak broadening of $\mathrm{ZnS}$ features occur between 560 and $650{ }^{\circ} \mathrm{C}$, suggesting that the size reduction is relatively fast in the above mentioned temperature regime; however, a longer heating time at lower temperatures or heating in dilute oxygen atmosphere is expected to generate similar changes in a controlled manner. ZS4 at $700{ }^{\circ} \mathrm{C}$ shows only a trace amount of $\mathrm{ZnS}$ features, suggesting an almost complete oxidation to $\mathrm{ZnO}$. An important underlying point in the above mentioned experiment is the controlled size reduction of $\mathrm{ZnS}$ between 400 and $650{ }^{\circ} \mathrm{C}$, which could be utilized to prepare a controlled $\mathrm{ZnS}$ particle size in the $\mathrm{ZS} x$ matrix. The above mentioned bottom-up approach is likely to control the crystallite size better than other methods, especially in the solid state. A simultaneous increase in the intensity of $\mathrm{ZnO}$ features further supports the oxidation of $\mathrm{ZnS}$ to $\mathrm{ZnO}$.

2.1.2. Surface Area Analysis. Nitrogen adsorption-desorption isotherms have been measured to investigate the textural properties of porous $\mathrm{ZS} x$ materials. Figure $3 \mathrm{a}$ shows the $\mathrm{N}_{2}$ adsorption-desorption isotherm results obtained at $77 \mathrm{~K}$ and analyzed by the Brunauer-Emmett-Teller method for surface area and Barrett-Joyner-Halenda (BJH) method for pore size distribution in Figure $3 b$; surface area and porosity have been calculated, and the results are given in Table 1. All materials show a type III adsorption-desorption isotherm with a $\mathrm{H} 3$ hysteresis loop that demonstrates the presence of mesopores and macropores. ${ }^{39}$ Predominantly, mesopores are observed for ZS1 with a surface area of $5 \mathrm{~m}^{2} / \mathrm{g}$ (Table 1 ). An increase in the amount of thiourea increases the surface area to 8 and $15 \mathrm{~m}^{2} / \mathrm{g}$ 


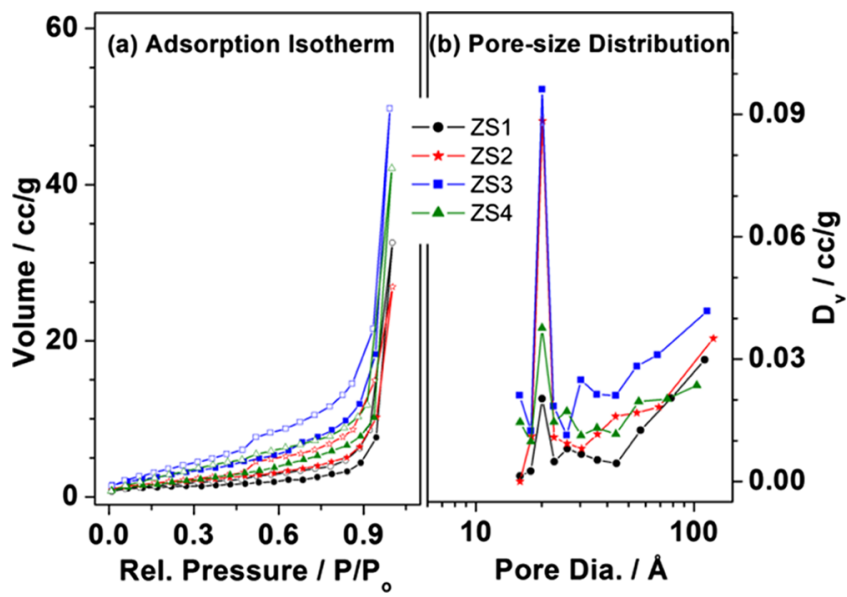

Figure 3. (a) $\mathrm{N}_{2}$ adsorption-desorption isotherms measured at $77 \mathrm{~K}$ and (b) BJH-pore size distribution pattern for ZS1, ZS2, ZS3, and ZS4 materials.

for ZS2 and ZS3, respectively, with marginal changes in the pore size and pore volume (not shown). In the case of ZS4, the surface area increases to $20 \mathrm{~m}^{2} / \mathrm{g}$ because of formation of more pores, and it is fully supported by microscopy results.

2.1.3. Thermogravimetric Analysis. Figure 4 depicts the thermal analysis of (a) ZS4 in air and $\mathrm{N}_{2}$ and (b) ZS1 and ZS2 in air atmosphere and compared with that of $\mathrm{ZnS}$ and $\mathrm{ZnSO}_{4} \cdot 7 \mathrm{H}_{2} \mathrm{O}$ (in b), respectively. $\mathrm{ZS} 1, \mathrm{ZS} 2$, and $\mathrm{ZS} 4$ shows about $2-3 \%$ weight loss up to $150{ }^{\circ} \mathrm{C}$ because of the elimination of water and adsorbed components. Between 150 and $570{ }^{\circ} \mathrm{C}$, the ZS4 material shows hardly any weight loss, and a sharp weight gain of $2.5 \%$ was observed between 570 and $680{ }^{\circ} \mathrm{C}$. Weight loss begins $>680{ }^{\circ} \mathrm{C}$ and continues up to $850{ }^{\circ} \mathrm{C}$. On comparison of ZS4 results with those of $\mathrm{ZnS}$ in air, it can be directly inferred that the weight gain between 570 and $680{ }^{\circ} \mathrm{C}$ is mainly due to the oxidation of $\mathrm{ZnS}$ to a sulfate/sulfite-like compound. Thermal analysis of a ZS4 material in an $\mathrm{N}_{2}$ atmosphere shows no weight gain between 500 and $650^{\circ} \mathrm{C}$, and a rather minor weight loss was observed between 600 and $700^{\circ} \mathrm{C}$, which clearly suggest that any oxidation is fully prevented in an $\mathrm{N}_{2}$ atmosphere. The thermogravimetry (TG) result in air atmosphere is supported by the XRD of a calcined material at different temperatures; however, no sulfate features observed in XRD (Figure 2) are attributed to the decomposition of sulfate species under in situ heating conditions. Besides, this also suggests that the reaction temperature under SCM conditions might be between 600 and $680{ }^{\circ} \mathrm{C}$ for sulfate formation in the cases of ZS1 and ZS2, and lower than $570{ }^{\circ} \mathrm{C}$ for ZS3 and ZS4. An exothermic peak observed in the differential thermal analysis (DTA) curve of ZS4 at $690{ }^{\circ} \mathrm{C}$ similar to that of $\mathrm{ZnS}$ at $660^{\circ} \mathrm{C}$ supports the oxidation of sulfide. A significant shift in the temperature of the above mentioned peak for ZS4 indicated a relatively better thermal stability for $\mathrm{ZS} x$ composites compared to bulk $\mathrm{ZnS}$. However, a shift of $+30{ }^{\circ} \mathrm{C}$ observed in the DTA exotherm for ZS4 is likely due to the distribution of smaller $\mathrm{ZnS}$ clusters in the wellprotected $\mathrm{ZnO}$ host lattice. It is well-known in the literature ${ }^{27,30}$ that the protected clusters, like the above mentioned, exhibit better thermal stability. Weight loss observed between 680 and $850{ }^{\circ} \mathrm{C}$ is due to decomposition of sulfate and/or oxysulfates of zinc to $\mathrm{ZnO}$ and the distribution of smaller clusters of $\mathrm{ZnS}$ in well-protected $\mathrm{ZnO}$, and it is in good correspondence with $\mathrm{ZnSO}_{4} \cdot 7 \mathrm{H}_{2} \mathrm{O}$ results (Figure $4 \mathrm{~b}$ ). No significant weight loss occurs above mentioned $850{ }^{\circ} \mathrm{C}$ and supports a complete removal of sulfur from ZS4. The weight loss pattern observed for $\mathrm{ZS} 1 / \mathrm{ZS} 2$ materials is quite different in air atmosphere compared to that for ZS4.

TG-DTA results of $\mathrm{ZnSO}_{4} \cdot 7 \mathrm{H}_{2} \mathrm{O}$ given in Figure $4 \mathrm{~b}$ is worth comparing with those of $\mathrm{ZS1} / \mathrm{ZS} 2$. For a pure $\mathrm{ZnSO}_{4} \cdot 7 \mathrm{H}_{2} \mathrm{O}$ compound, there is an initial weight loss of about $42 \%$ up to 250 ${ }^{\circ} \mathrm{C}$ in two phases; this is due to the loss of water of crystallization. About 5-6\% weight loss observed up to $270{ }^{\circ} \mathrm{C}$ on ZS1/ZS2 is mainly due to adsorbed water. A sharp weight loss of $29 \%$ observed between 700 and $880{ }^{\circ} \mathrm{C}$ for $\mathrm{ZnSO}_{4} \cdot 7 \mathrm{H}_{2} \mathrm{O}$ is attributed to the decomposition of sulfate to oxide. Indeed, the weight loss observed between 600 and $850{ }^{\circ} \mathrm{C}$ (Figure 4a) is due to the decomposition of $\mathrm{ZnSO}_{4}$ to $\mathrm{ZnO}$. The loss of $\mathrm{SO}_{2} / \mathrm{SO}_{3}$ leads to weight loss in TG. It is to be noted the endothermic nature of $\mathrm{ZnSO}_{4}$ decomposition, in contrast to the exothermic oxidation of

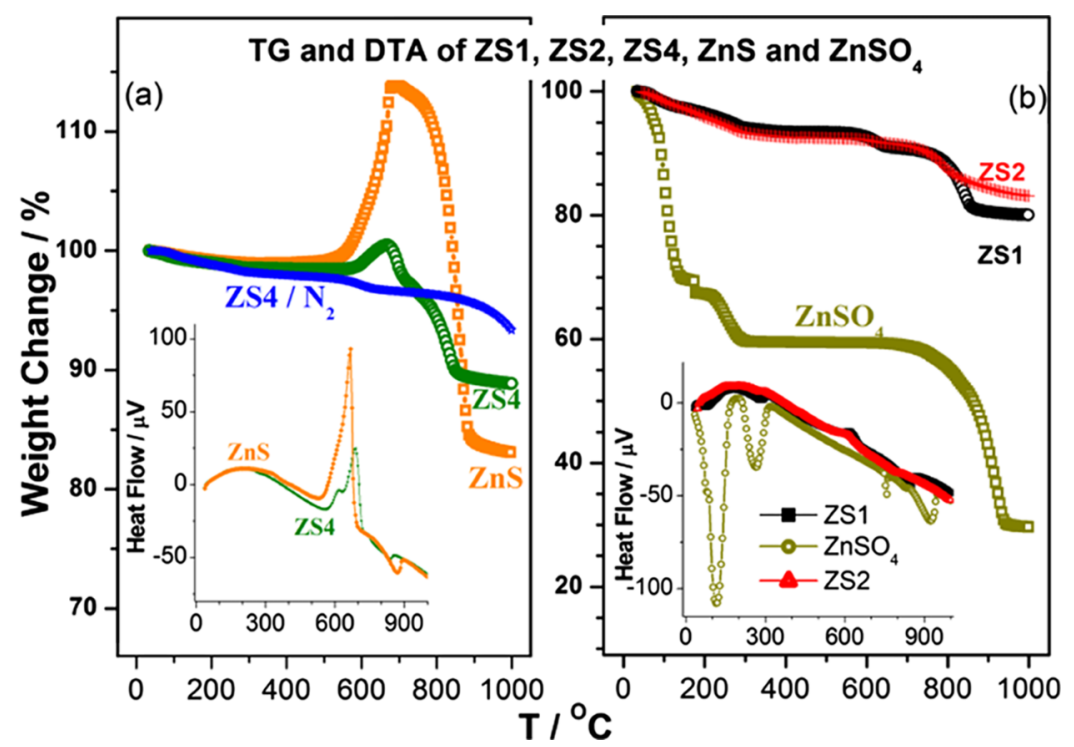

Figure 4. Thermogravimetric analysis of (a) $\mathrm{ZS4}$ and $\mathrm{ZnS}$ and (b) $\mathrm{ZS1}, \mathrm{ZS} 2$, and $\mathrm{ZnSO}_{4} \cdot 7 \mathrm{H}_{2} \mathrm{O}$ carried out in air (and nitrogen for ZS4) atmosphere at a heating rate of $10{ }^{\circ} \mathrm{C} / \mathrm{min}$. DTA of respective materials carried out in air atmosphere is given in the corresponding insets. 

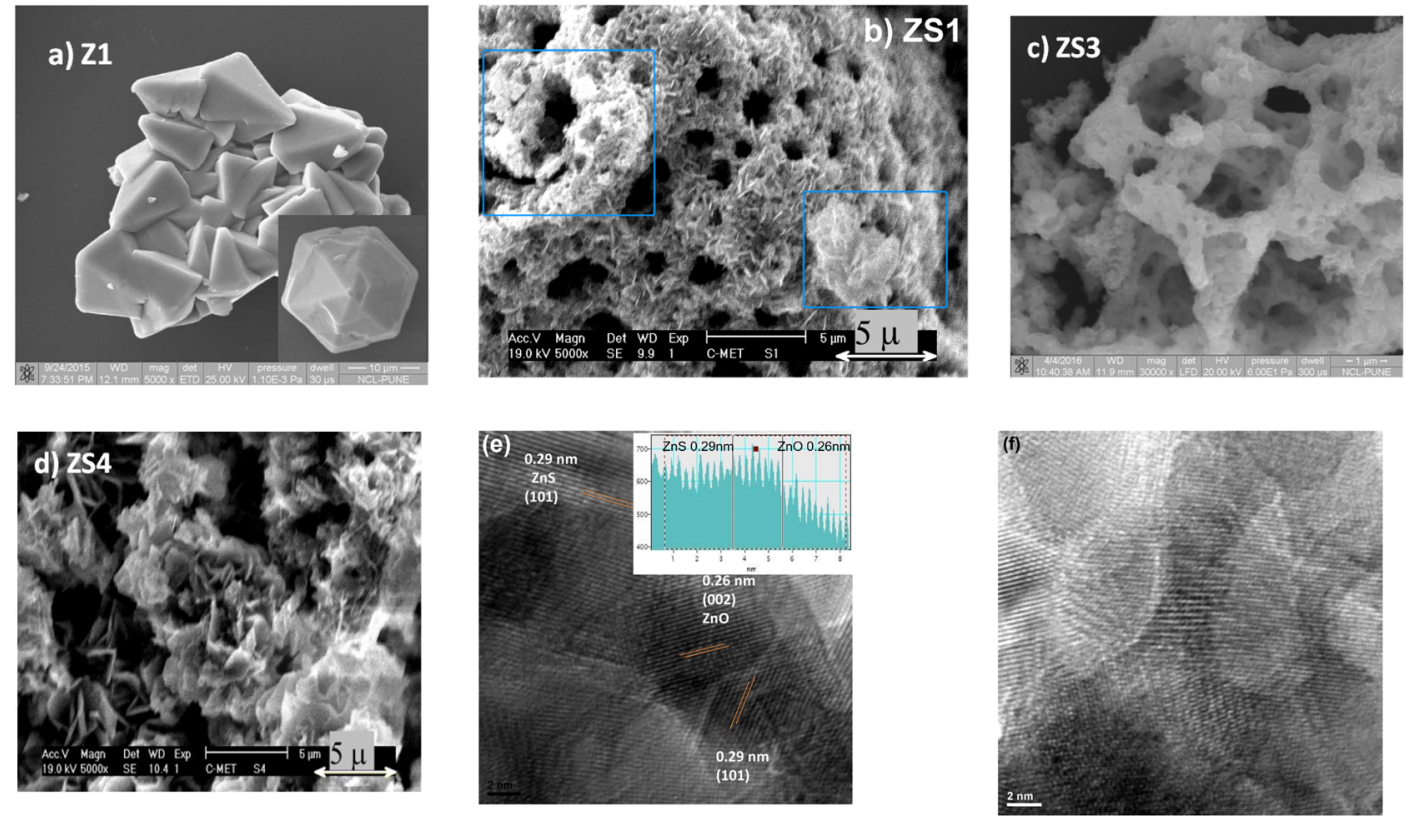

Figure 5. SEM images of (a) Z1, (b) ZS1, (c) ZS3, and (d) ZS4 and HRTEM images of (e) ZS3 and (f) ZS4. Transparent white patches (indicated by blue squares) observed on ZS1 are due to sulfate/sulfite. One-dimensional needle-shaped particles observed on ZS1 change to V-shaped morphology on ZS4. Z1 shows triangle and hexagonal prisms in panel (a). Inset in panel (e) shows line profile analysis to show a progressive change in the $d$ value from $\mathrm{ZnS}$ to $\mathrm{ZnO}$ measured in the bottom-right side. The number of heterojunctions is evident in ZS3 and ZS4 given in panels (e,f).

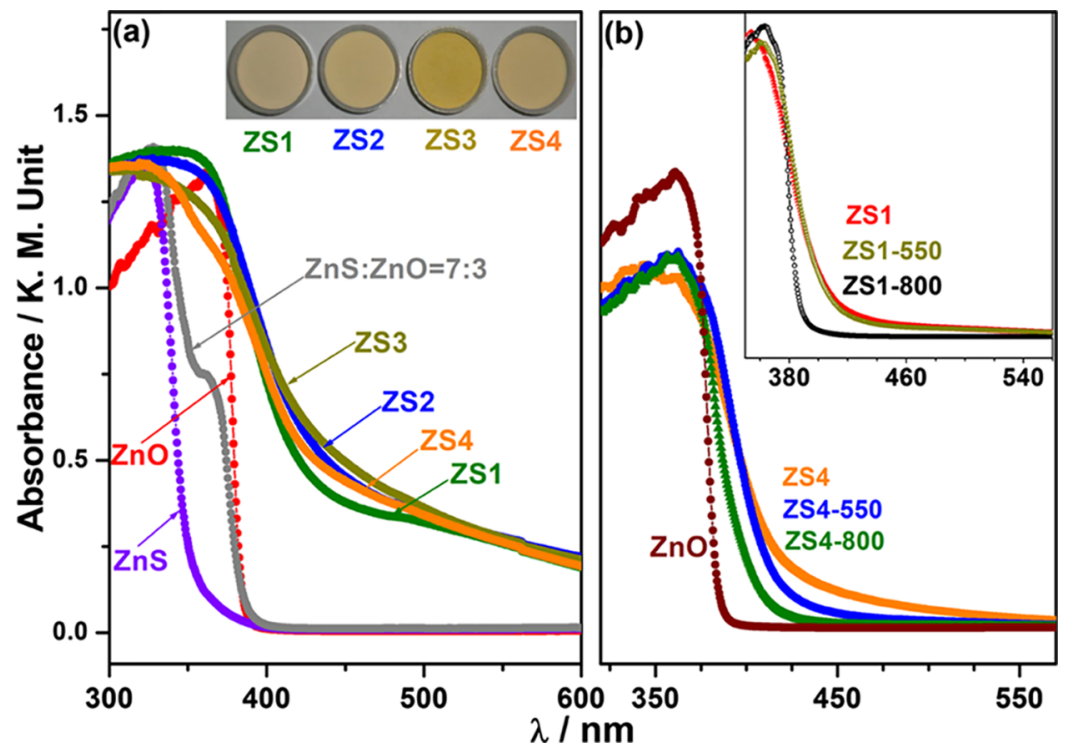

Figure 6. (a) Diffuse reflectance UV-vis spectra of the $\mathrm{ZS} x$ materials along with $\mathrm{ZnO}$, $\mathrm{ZnS}$, and a physical mixture of $\mathrm{ZnS}$ and $\mathrm{ZnO}$ (7:3). A digital photograph is shown in the inset of panel (a) for the color associated with ZSx. (b) Diffuse reflectance UV-vis spectra of ZS4 (inset ZS1) materials calcined at 550 and $800{ }^{\circ} \mathrm{C}$ and $\mathrm{ZnO}$.

$\mathrm{ZnS}$ to $\mathrm{ZnSO}_{4}$ followed by decomposition. In a similar manner, ZS1 and ZS2 show a weight loss of 13 and 7\%, respectively, between 550 and $850{ }^{\circ} \mathrm{C}$. Low weight loss with ZS2 hints at a low sulfate and high $\mathrm{ZnS}$ content.

2.1.4. SEM and HRTEM. The morphology and the textural properties of $\mathrm{ZS} x$ materials were explored using scanning electron microscopy (SEM) and high-resolution transmission electron microscopy (HRTEM). From the SEM images of asprepared ZSx materials shown in Figure 5, it is clear that the materials exhibit pores of the order of $1-10 \mu \mathrm{m}$, and they are macroporous in nature. The porous nature of the materials was well-supported by surface area analysis. It is also important to compare the morphology and textural properties of $\mathrm{Z} 1$ to $\mathrm{ZS} x$ materials. Z1 shows a ordered hexagonal pyramid without any pore. ${ }^{16}$ Indeed, the well-ordered microcrystals observed in Figure 5a for $\mathrm{Z1}$ highlights the compact micro crystals of $\mathrm{ZnO}_{1-x} \mathrm{~N}_{x}$; an enlarged image of a single hexagonal particle from the top view is shown in the Figure 5a inset. Further, the surface area of $Z 1$ is also very low at $1 \mathrm{~m}^{2} / \mathrm{g}$, which underscores the above mentioned point. ZS1 shows a porous structure with a needleshaped particle, highlighting the role of thiourea in changing the surface and particle morphology.

Needle-shaped one-dimensional particles observed predominantly are attributed to ZS1 and ZS2, and transparent white 
patches observed on ZS1 (at top left and bottom right above the scale bar on Figure 5b) are attributed to sulfate-/sulfite-related compounds on the surface. On moving from ZS1 to ZS4, the above mentioned sulfate-related compounds decrease in content, and the particle morphology also changes drastically from a onedimensional needle to two-dimensional V-shaped arrays with an edge size of about $1.5 \mu \mathrm{m}$ at an angle of $72^{\circ}$. Indeed, the surface area also increases from 5 to $20 \mathrm{~m}^{2} / \mathrm{g}$ from ZS1 to ZS4, respectively, indicating an increased porosity from ZS1 to ZS4. EDX analysis was carried out to measure the material composition as well as to find out the extent of uniform distribution over a large surface area $\left(1 \mathrm{~mm}^{2}\right)$. Representative EDX results are given in Figure S2 for ZS2 and ZS4, and they support uniform distribution of all elements.

HRTEM results of ZS3 and ZS4 are shown in Figure 5e,f, respectively. Distinct $d$-spaces observed $(0.29$ and $0.26 \mathrm{~nm}$ ) correspond to $\mathrm{ZnS}(101)$ and $\mathrm{ZnO}(002)$ facets, respectively, in both panels. Careful analysis reveals the abundant availability of heterojunctions between $\mathrm{ZnO}$ and $\mathrm{ZnS}$ and confirms the formation of $\mathrm{ZnO}-\mathrm{ZnS}$ heterojunctions. Indeed, many such heterojunctions observed in several samples, prepared in different batches hints at the reliability of the method and measurements. Line profile analysis shown in the Figure 5e inset shows a clear change in the $d$ value from $\mathrm{ZnS}$ to $\mathrm{ZnO}$. The central rectangular box shows a gradual change in $\mathrm{ZnS}$ to $\mathrm{ZnO}$. In fact, this indicates a possibility of the presence of solid solution to some extent. Thiourea and urea dissociate to generate in situ ammonia and $\mathrm{H}_{2} \mathrm{~S}$ gaseous products at $500{ }^{\circ} \mathrm{C}$, which helps to form $\mathrm{ZS} x$ composites with $\mathrm{ZnO}-\mathrm{ZnS}$ heterojunctions.

2.1.5. Optical Absorption. It is well-known that anion doping affects light absorption characteristics of any oxide material, ${ }^{19}$ and $\mathrm{ZnO}$ is not an exception. Diffuse reflectance UV-visible spectra of ZS $x$ composites are shown in Figure 6a and compared with reference materials $[\mathrm{ZnS}, \mathrm{ZnO}$, and a physical mixture $(\mathrm{ZnS}-\mathrm{ZnO}=7: 3)]$. It is to be noted that $\mathrm{ZnS}$ and $\mathrm{ZnO}$ show absorption cutoff around 340 and $375 \mathrm{~nm}$, respectively. However, the absorption cutoff is extended, at least, to $470 \mathrm{~nm}$ for all ZSx materials; ZS4 shows absorption up to $550 \mathrm{~nm}$. A red shift is observed with increasing $\mathrm{ZnS}$ content from ZS1 to ZS4, and it is attributed to the modified chemical environment because of the formation of the heterojunction of $\mathrm{ZnS}$ and $\mathrm{ZnO}$. Further $\mathrm{ZnS}$ crystallite sizes measured from XRD (Figures 1 and 2) suggest an increasing size from $Z S 1$ to $Z S 4$ which is in good agreement with the above mentioned red shift.

This is further confirmed from the absorption spectrum recorded for a 7:3 physical mixture of $\mathrm{ZnS}-\mathrm{ZnO}$, which exhibits absorption due to $\mathrm{ZnS}$ up to $340 \mathrm{~nm}$ and up to $375 \mathrm{~nm}$ due to $\mathrm{ZnO}$, as expected. A physical mixture of any ratio of $\mathrm{ZnS}$ and $\mathrm{ZnO}$ does not exhibit absorption $>375 \mathrm{~nm}$ supporting $\mathrm{ZS} x$ with heterojunctions between $\mathrm{ZnS}$ and $\mathrm{ZnO}$. Band gap energies calculated from the diffuse reflectance spectroscopy results for $\mathrm{ZS} x$ show a prominent decrease with increasing $\mathrm{ZnS}$ content. The band gap calculated from the absorption spectral data for ZS4 is $2.67 \mathrm{eV}$, suggesting a significant band gap reduction and changes in the electronic structure of $\mathrm{ZS} x$ composites compared to the pure components. However, a careful analysis of absorption by ZS3 and ZS4 reveals that the former absorbs more visible light with a considerably high absorption coefficient, especially between 400 and $500 \mathrm{~nm}$. The band gap diminution of the $\mathrm{ZS} x$ composites has been attributed to the formation of hybrid bands/orbitals of $\mathrm{ZnO}$ and $\mathrm{ZnS}$ at the heterojunctions or interfaces. It is expected that $S 3 p$ and $O 2 p$ are likely to overlap in the VB, and the extent of overlap increases from ZS1 to ZS4 because of the increasing extent of heterojunctions. Sulfur exists as an anion $\left(\mathrm{S}^{2-}\right)$ in $\mathrm{ZS} 3$ and $\mathrm{ZS} 4$, and the top of $\mathrm{VB}$ might be predominantly composed of $S 3 p$ energy levels, as they have higher orbital energies than $\mathrm{O} 2 \mathrm{p}$ levels. Thus, in the VB of ZS $x, S$ $3 \mathrm{p}$ and $\mathrm{O} 2 \mathrm{p}$ bands overlap and broaden the $\mathrm{VB}$ than in $\mathrm{ZnO}$ or $\mathrm{ZnS}$. It is expected that the CB of ZS1-ZS4 is formed by $\mathrm{Zn} 3 \mathrm{~d}$ as well as $S 3 \mathrm{~d}$ orbitals. Our experimental results are in good agreement with DFT predictions by Schrier et al. ${ }^{13 \mathrm{~b}}$ for the $\mathrm{ZnO}-\mathrm{ZnS}$ planar superlattice with a band gap of $2.31 \mathrm{eV}$. ZS1 and ZS4 calcined at high temperatures have been subjected to optical absorption studies, and the results are shown in Figure $6 \mathrm{~b}$. They exhibit a systematic decrease in the visible light absorption at calcination temperatures $>550{ }^{\circ} \mathrm{C}$.

2.1.6. X-ray Photoelectron Spectroscopy. Core-level spectra of $S 2 p$ and $N$ 1s are compared in Figure 7, and the results from

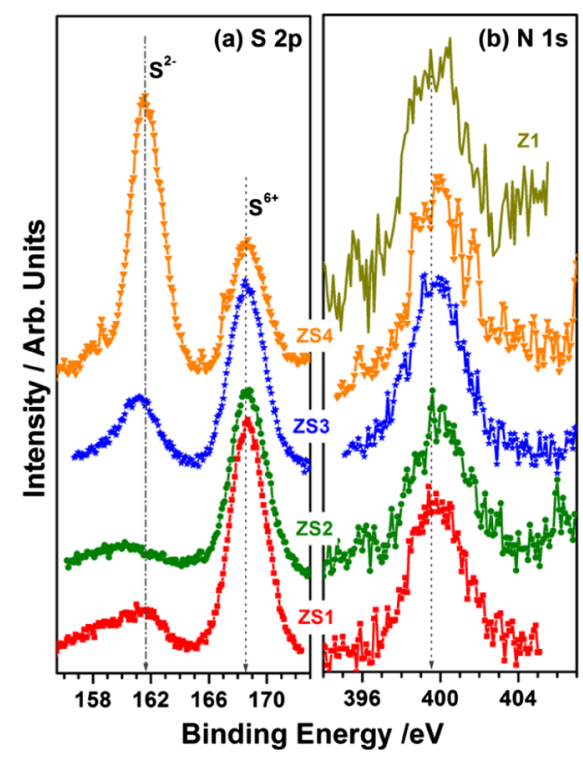

Figure 7. X-ray photoelectron spectroscopy spectra obtained from (a) $S$ $2 \mathrm{p}$ and (b) N 1s core levels of ZSx.

$\mathrm{Zn} 2 \mathrm{p}_{3 / 2}$, O $1 \mathrm{~s}$, and survey spectra are given in the Supporting Information (Figure S3). It can be seen from Figure 7a that the $S$ $2 p$ core level displays two different peaks at binding energy $(\mathrm{BE})$ around 168.5 and $161.5 \mathrm{eV}$. A comparison of the observed BE to that of reported values for different sulfur compounds demonstrates that the oxidation state of $S$ at $161.5 \mathrm{eV}$ is due to $\mathrm{S}^{2-}$ as in typical sulfides, and at $168.5 \mathrm{eV}$ is due to $\mathrm{S}^{6+}$ as in sulfate or oxysulfate. ${ }^{13}$ The peak at $161.5 \mathrm{eV}$ corresponds to $\mathrm{ZnS}$ and demonstrates the formation of $\mathrm{ZnS}$ in ZSx. On ZS1 and ZS2, a characteristic, but broad, peak for sulfide was found with low intensity, along with a majority of sulfate on the surface. The sulfide feature increases in intensity from ZS1 to ZS4 and directly supports the observation of XRD. The above mentioned observation supports the oxidation of sulfide species on the surface to sulfate under preparation conditions. Nonetheless, sulfate formation is mostly restricted to the surface on ZS3 and ZS4, and no feature corresponding to sulfate has been observed in any of the bulk characterizations, such as XRD, Raman, and secondary-ion mass spectrometry (SIMS). It is clear from Figure $7 \mathrm{a}$ that with increasing thiourea content in the preparation mixture, the total sulfur content on the surface increases, which was demonstrated in the elemental mapping of ZS4 (Figure S2f). This can be clearly seen in the prepared material (in ZS3 and ZS4), where a prominent peak for sulfide and some sulfate was 
observed. Because of combustion conditions, some sulfate formation on the surface cannot be avoided; however, it can be removed by simple washing with water.

The $\mathrm{N}$ 1s core level appears at around $399.5 \pm 0.2 \mathrm{eV}$ for all $\mathrm{ZS} x$ (Figure $7 \mathrm{~b}$ ) materials, suggesting the nature of nitrogen on the surface, especially that the charge density is similar to that of ammonia. ${ }^{16}$ It is also surprising that the nature of $\mathrm{N}$ remains the same on all $\mathrm{ZS} x$ compositions and increasing $\mathrm{ZnS}$ content did not change the nature. However, no nitride phase such as $\mathrm{Zn}_{3} \mathrm{~N}_{2}$ was found. Moreover, the amount of surface nitrogen decreases from $\mathrm{Z} 1$ to $\mathrm{ZS} 4$, and it is also in correspondence to the bulk $\mathrm{N}$ content (Table 1) estimated by EDX. We attribute this trend to the $\mathrm{N}$ doping in the $\mathrm{ZnO}$ lattice, and no significant role in photocatalysis is expected, which is in line with $\mathrm{ZnO}_{1-x} \mathrm{~N}_{x}{ }^{16}$ The $\mathrm{BE}$ values for the $\mathrm{Zn} 2 \mathrm{p}_{3 / 2}$ region was found at $1021.9 \pm 0.1 \mathrm{eV}$, which is in agreement with literature values reported for $\mathrm{ZnO}$ $(1022 \mathrm{eV})$ and $\mathrm{ZnS}(1021.9 \mathrm{eV})$ (see the Supporting Information Figure S3). ${ }^{16,26}$ The O 1s core level also shows a typical oxide feature for $\mathrm{Z} 1$ at $529.4 \mathrm{eV}$. Nonetheless, the main $\mathrm{O}$ 1s peak appears at $531.8 \mathrm{eV}$ for all $\mathrm{ZS} x$ materials uniformly because of sulfate, whereas the $\mathrm{ZnO}$ feature was suppressed because of preferential sulfate formation.

2.1.7. Raman Spectra. Raman spectra of ZSx materials along with $\mathrm{Z1}, \mathrm{ZnO}$, and $\mathrm{ZnS}$ were measured, and the results are shown in Figure 8. Distinct Raman modes $\left\{\mathrm{E}_{2}\right.$, longitudinal optical $\left[\mathrm{A}_{1}(\mathrm{LO})\right]$ and transverse optical $\left.\left[\mathrm{A}_{1}(\mathrm{TO})\right]\right\}$ are observed for $\mathrm{ZnO}, \mathrm{ZnS}$, and $\mathrm{Z1}{ }^{39} \mathrm{ZnS}$ shows characteristic phonon modes with high intensity at $428\left(2 \mathrm{E}_{2}\right)$ and $711 \mathrm{~cm}^{-1}\left[\mathrm{~A}_{1} / \mathrm{E}_{1}(2 \mathrm{LO})\right]$, and two other features at 492 and $611(2 \mathrm{TO}) \mathrm{cm}^{-1}$. All the above mentioned four modes were observed for ZS1 to ZS4 materials. A strong and sharp peak observed at $433 \mathrm{~cm}^{-1}$ on all ZS $x$ materials, $437 \mathrm{~cm}^{-1}$ on $\mathrm{ZnO}$, and $429 \mathrm{~cm}^{-1}$ on $\mathrm{ZnS}$ is due to the typical $\mathrm{E}_{2}$ (high) mode, and this mode is characteristic of the wurtzite phase. Among the Raman modes, the $\mathrm{E}_{2}$ (high) at 437 $\mathrm{cm}^{-1}$ shows the strongest intensity in $\mathrm{ZnO}$ and on all $\mathrm{ZS} x$ materials, indicating the high quality of the material. The presence of the above mentioned mode in $\mathrm{ZS} x$ materials indicates that they exhibit the same local geometry. Nonetheless, it is to be noted that all $\mathrm{ZS} x$ materials exhibit the $2 \mathrm{E}_{2}$ mode at 433 $\mathrm{cm}^{-1}$ and exactly in between the $\mathrm{E}_{2}$ modes of $\mathrm{ZnO}$ and $\mathrm{ZnS}$, indicating the strong interaction of $\mathrm{ZnO}$ and $\mathrm{ZnS}$ with the formation of the heterojunction nature of $\mathrm{ZS} x$ materials. Broadand low-intensity features observed for ZS1 are likely due to sulfate species present in it; however, no new mode for sulfate species was observed. Indeed, it is surprising that first-order $E_{2}$ and $A_{1} / E_{1}(L O)$ phonon modes are not observed; rather secondorder $2 \mathrm{E}_{2}$ and $\mathrm{A}_{1} / \mathrm{E}_{1}(2 \mathrm{LO})$ modes are observed with high intensity for $\mathrm{ZnS}$ as well as $\mathrm{ZS} x$. In addition to the above, broad peaks are observed at $497 \mathrm{~cm}^{-1}$ on ZS $x$ materials, which does not belong to the first- or second-order structure of neither $\mathrm{ZnO}$ nor $\mathrm{ZnS}$; further, this mode is not observed for ZS1, suggesting that this is not due to sulfate-related species also. Although XRD does not show prominent $\mathrm{ZnS}$ features for ZS2, Raman results show the same, highlighting the formation of $\mathrm{ZnS}$ in ZS2. Sharp peaks at 507 and $582 \mathrm{~cm}^{-1}$ in $\mathrm{Z} 1$ are attributed to $\mathrm{A}_{1}(\mathrm{LO})$ due to $\mathrm{N}$ doping. ${ }^{16,39}$

2.1.8. SIMS Analysis. SIMS analysis results obtained are shown in Figure 9. Initially, the recorded mass spectrum (not shown) demonstrated the presence of different species, namely, $\mathrm{Zn}, \mathrm{S}, \mathrm{ZnO}, \mathrm{ZnN}, \mathrm{ZnS}, \mathrm{N}$, and $\mathrm{O}$ with significant to high counts. Secondary-ion intensities of the first five species are shown in Figure 9, as a function of sputtering time or depth. No change in counts/intensity of any species with sputtering time emphasizes

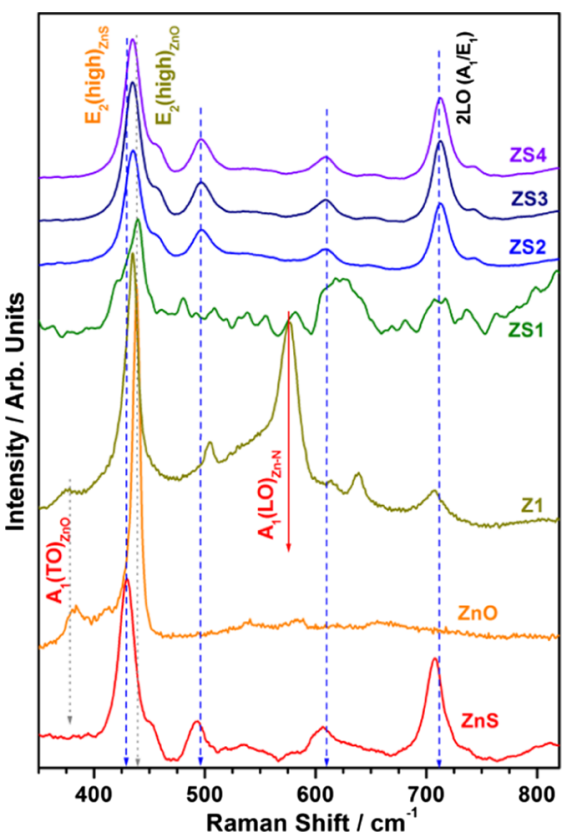

Figure 8. Raman spectra of $\mathrm{ZS} x$ materials, compared with $\mathrm{Z} 1, \mathrm{ZnS}$, and $\mathrm{ZnO}$.

the introduction of $S$ throughout the bulk of $\mathrm{ZS} x$ and the uniformity of the distribution throughout the bulk. Further, Srelated fragments dominate over $\mathrm{N}$-related fragments, indicating that the $\mathrm{N}$ content is relatively lower. This is further confirmed from the SIMS results from $\mathrm{Z} 1$, in which $\mathrm{N}$ and $\mathrm{Zn}-\mathrm{N}$ exhibit higher intensity than $\mathrm{Zn}-\mathrm{N}$ in $\mathrm{ZS} x{ }^{16}$ Indeed, any species that exhibits 10 counts/s and less is not considered because of low signal/noise and poor reliability.

It is fully surprising that a heavier element like $S$ does compete with $\mathrm{N}$, and preferential $\mathrm{ZnS}$ formation occurs under combustion conditions. Nonetheless, counts for all species were significantly different on Z1, ZS1, and ZS4, indicating that the material characteristic has changed significantly from each other. Higher count rates are observed for $\mathrm{Zn}-\mathrm{N}$ than $\mathrm{Zn}-\mathrm{O}$ fragments, despite $\mathrm{ZnO}$ being the host lattice in $\mathrm{Z1}$, which is attributed to the different ionization capacity of emitted species, and this is strongly dependent on the local surface characteristics of the materials, known as the matrix effect. ${ }^{40}$ Although the bulk N content in ZS1 is half that of $\mathrm{Z1}$, very low $\mathrm{Zn}-\mathrm{N}$ fragments observed on ZS1 reiterates that the ionization capacity varies for the same fragment from material to material, especially when the nature of the materials changed significantly. An important point to be mentioned here is that no other $\mathrm{N}$ - and S-related species, such as $\mathrm{N}_{2}, \mathrm{NO}, \mathrm{ZnNO}, \mathrm{ZnSO}, \mathrm{NH}_{x}, \mathrm{SO}_{x}(x=1-4)$, and $\mathrm{NS}$, are observed in SIMS, which suggests that the status of $\mathrm{N}$ and $\mathrm{S}$ in $\mathrm{ZnO}_{1-x} \mathrm{~N}_{x}$ and $\mathrm{ZS} x$ materials is none of the above. It is also surprising to note the absence of $\mathrm{SO}_{x}$, in spite of sulphate/ sulphite species observed in other methods. As indicated by other characterizations, the nature of sulfur changes increasingly toward sulfide from ZS1 to ZS4.

2.1.9. Chronoamperometry. Photo-electrochemical measurement was carried out using three electrode assemblies in a 0.5 $\mathrm{M} \mathrm{NaClO}_{4}$ electrolyte to understand the light harvesting character. A photoresponsive material was casted on a fluorinedoped tin oxide plate and evaluated for photocurrent generation under illumination. Chronoamperometry measurement (at $0 \mathrm{~V}$ vs $\mathrm{Ag} / \mathrm{AgCl}$ ) was carried out to study the instantaneous photoresponse of the materials, and the results are shown in 


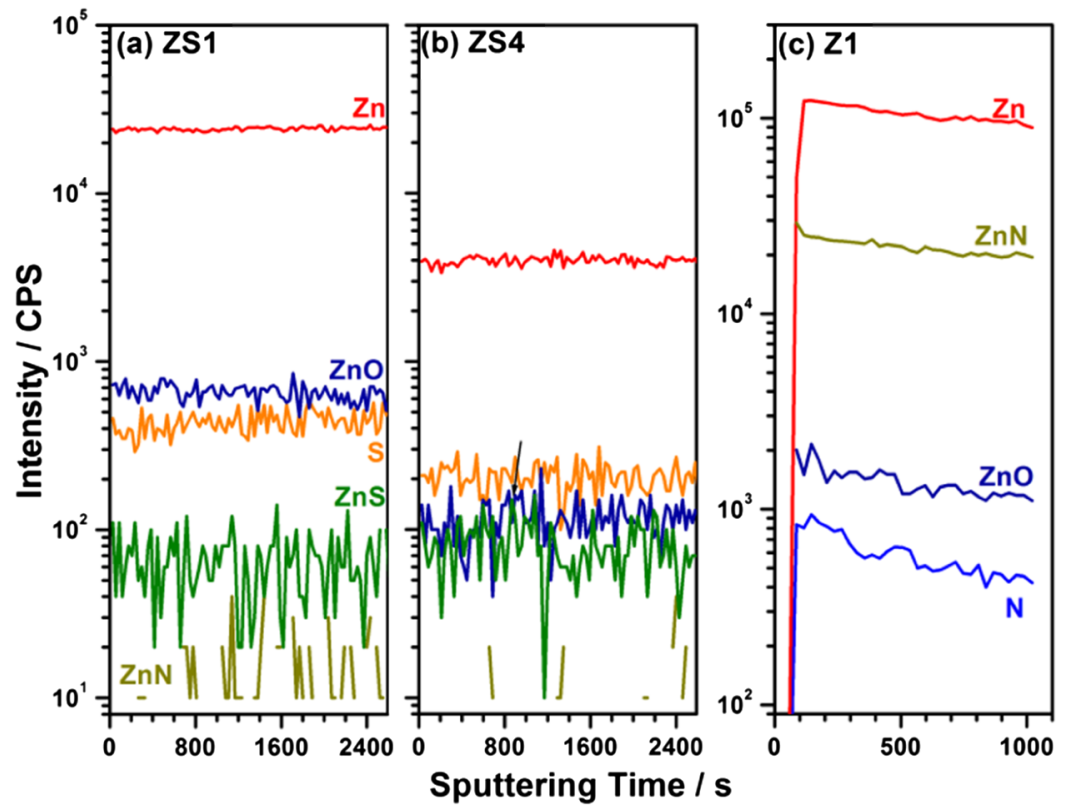

Figure 9. SIMS results display secondary-ion intensities measured as a function of sputtering depth or time for (a) ZS1, (b) ZS4, and (c) Z1.

Figure 10. Two types of measurements were carried out, namely, AM $1.5\left(100 \mathrm{~mW} / \mathrm{cm}^{2}\right)$ and with a $400 \mathrm{~nm}\left(92 \mathrm{~mW} / \mathrm{cm}^{2}\right)$ cutoff filter to follow the photocurrent change and efficiency of visible light absorption. Among all catalysts, ZS4 generates an at least 4fold and 2-fold higher current than ZS1 or ZS2, and ZS3, respectively (Figure 10a) under irradiation conditions. It demonstrates the effective absorption of light by ZS4, and the large number of heterojunctions present helps achieve high current than other compositions; in fact, the high surface area and porosity associated with ZS4 helps this. No current was produced under dark (shutter close) conditions, confirms the photofunctional behavior of $\mathrm{ZS} x$ materials. The photocurrentgenerated value shows less in the visible light region than AM 1.5 (Figure 10a) because of no UV light in the $400 \mathrm{~nm}$ filtered light (Figure 10b). This observation demonstrates the necessity to utilize the small amount UV light (4-5\%) in the solar radiation ( 1 sun condition) to maximize solar harvesting. Further, 3.5-fold higher current generation observed for ZS4 than ZS3 underscores the effective absorption of visible light (Figure 10b) and charge separation by ZS4. High photocurrent generated from

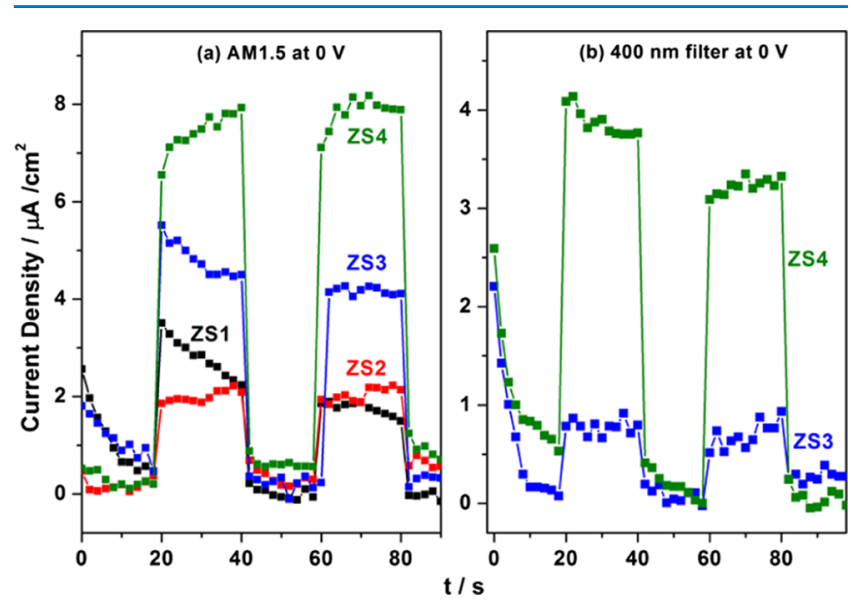

Figure 10. Photocurrent measurement under (a) AM1.5 (ZS1, ZS2, ZS3, and ZS4) and (b) $400 \mathrm{~nm}$ (ZS4 and ZS3).
ZS4 is attributed to better necking between the particles, which is essential for electron conduction. The extent of necking is relatively higher with ZS4 than ZS3, and hence the former shows higher current. Because of high photocurrent generation, ZS4 and ZS3 show better quantum efficiency in DSSC measurement and high photocatalytic degradation of ECD than ZS1 or ZS2, which is described below.

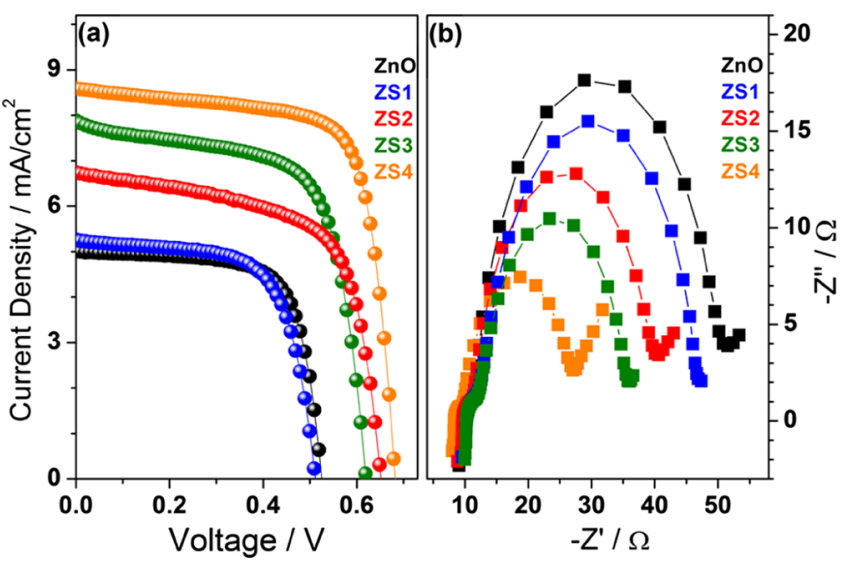

Figure 11. (a) $J-V$ curves of (DSSCs) $\mathrm{ZnO}, \mathrm{ZS} 1, \mathrm{ZS} 2, \mathrm{ZS} 3$, and ZS4. (b) Nyquist plots of all PV cells under AM 1.5G sun illumination (100 $\left.\mathrm{mW} / \mathrm{cm}^{2}\right)$.

\section{DYE-SENSITIZED SOLAR CELLS}

Figure 11 a and Table 2 show the $J-V$ curves and the photovoltaic (PV) performances of DSSC devices, respectively, based on the photoanodes using $\mathrm{ZnO}$ and $\mathrm{ZS} x$ composites under 1 sun irradiation (AM 1.5G solar simulation). Typical ZnO-based cells exhibit $V_{\mathrm{oc}}-0.53 \mathrm{~V}, J_{\mathrm{sc}}-4.95 \mathrm{~mA} / \mathrm{cm}^{2}$, fill factor (FF) $-59 \%$, and $\eta-1.53 \%$. The PV performance linearly increases by varying the composition of sulfur from ZS1 to ZS4. ZS4 exhibits the best 
Table 2. PV Parameters of $\mathrm{ZnO}$ and $\mathrm{ZS} x$ Composites under AM $1.5 \mathrm{G}$ Sun Illumination $\left(100 \mathrm{~mW} / \mathrm{cm}^{2}\right)$

\begin{tabular}{|c|c|c|c|c|c|}
\hline parameters $^{a}$ & $\mathrm{ZnO}$ & $\mathrm{ZS} 1$ & ZS2 & ZS3 & ZS4 \\
\hline$V_{\mathrm{oc}}(\mathrm{V})$ & 0.53 & 0.51 & 0.64 & 0.62 & 0.67 \\
\hline$J_{\mathrm{sc}}\left(\mathrm{mA} / \mathrm{cm}^{2}\right)$ & 4.95 & 5.3 & 6.7 & 7.9 & 8.45 \\
\hline FF (\%) & 0.59 & 61 & 63 & 64 & 67 \\
\hline$\eta(\%)$ & $1.54 \pm 0.23$ & $1.64 \pm 0.27$ & $2.7 \pm 0.2$ & $3.1 \pm 0.24$ & $3.8 \pm 0.3$ \\
\hline$R_{\mathrm{ct}}(\Omega)$ & 43 & 39 & 33 & 28 & 23 \\
\hline$C_{\mu}\left(\mu \mathrm{F} / \mathrm{cm}^{2}\right)$ & 3.1 & 6.73 & 10.1 & 13.5 & 18.4 \\
\hline$\tau_{\mathrm{r}}(\mathrm{ms})$ & 1.33 & 2.62 & 3.31 & 3.78 & 4.1 \\
\hline IPCE (\%) & 30 & 32 & 36 & 38 & 48 \\
\hline
\end{tabular}

${ }^{a}$ Active photoanode area $=0.235 \mathrm{~cm}^{2}$. Thickness of material is $15 \mu \mathrm{m}$ dipped into $0.5 \mathrm{mM}$ of acetonitrile/tert-butanol $(1: 1)$ for $6 \mathrm{~h}$.

PV performance $\left(V_{\text {oc }}-0.67 \mathrm{~V} ; J_{\mathrm{sc}}-8.45 \mathrm{~mA} / \mathrm{cm}^{2} ; \mathrm{FF}-69 \%\right.$; and $\eta-3.8 \%)$ than other $\mathrm{ZS} x$ materials and bare $\mathrm{ZnO}$. This was further confirmed by the incident photon conversion efficiency (IPCE) spectra (see Figure S4 in the Supporting Information), wherein bare $\mathrm{ZnO}$ shows $30 \%$ conversion and ZS4 shows $48 \%$. The SEM results reveal the porous nature and the high surface area for ZS4, which induce the photogenerated carriers to diffuse fast to the surface and react rapidly with the adsorbed molecules. More interestingly, the effective transport of charge carriers at the heterojunction between $\mathrm{ZnO}$ and $\mathrm{ZnS}$ helps to minimize the recombination which is proven by high FF (69\%) for ZS4.

Electrochemical impedance spectroscopy (EIS) is a powerful tool to investigate the internal resistance and the charge-transfer process in DSSC. ${ }^{41}$ Charge-transfer resistance $\left(R_{\mathrm{ct}}\right)$ of $\mathrm{ZnO}$ and the composites were obtained from Nyquist plots (Figure 11b) under light illumination $\left(100 \mathrm{~mW} / \mathrm{cm}^{2}\right)$ at the photoelectrode/ electrolyte interface. From the EIS analysis, $R_{\mathrm{ct}}\left(C_{\mu}\right)$ and electron lifetime $\left(\tau_{\mathrm{r}}\right)$ were calculated and are summarized in Table 2. $\tau_{\mathrm{r}}$ was calculated by the following equation; $\tau_{\mathrm{r}}=R_{\mathrm{ct}} \times C_{\text {chem }} ;\left(C_{\mathrm{chem}}\right.$ $=$ chemical capacitance). $\tau_{\mathrm{r}}$ reflects the response time constant for recombination which is correlated with $V_{\text {oc }}$. A ZS4-based photoanode exhibited the smallest charge-transfer resistance (23 $\Omega)$, with highest chemical capacitance $\left(18 \mu \mathrm{F} / \mathrm{cm}^{2}\right)$ and electron lifetime $(4.1 \mathrm{~ms})$, indicating faster charge transport and lower recombination across the interface of photoelectrode. Compared to ZS4, all other ZSx composites show higher $R_{\mathrm{ct}}$, and $\tau_{\mathrm{r}}$ and smaller $C_{\text {chem. }}$. This underscores the better charge separation characteristics associated with ZS4, which is expected to generally increase the solar harvesting performance.

3.1. Photocatalytic Degradation of 2,4-DCP in Direct Sun Light. 2,4-DCP can be considered as a model compound for ECD, and its degradation was carried out as a model reaction to evaluate the photocatalytic oxidation ability of ZSx. Figure 12 shows the UV-vis absorption spectrum recorded for aqueous 2,4-DCP solution that was irradiated under direct sun light for different time periods with ZS3 (Figure 12a) and ZS4 (Figure 12b). Two absorption bands (broad band below 240 and at 285 $\mathrm{nm}$ ) are observed for $100 \%$ DCP or before the onset of degradation; the weaker band in $270-300 \mathrm{~nm}$ range corresponds to $\pi-\pi^{*}$ and $\mathrm{n}-\pi^{*}$ transitions that are characteristic of benzene and its substituted derivatives. ${ }^{42}$ Significant photocatalytic degradation is evident from the results observed in Figure 12 by ZS3 and ZS4. A linear decrease in 2,4-DCP degradation is evident from the decrease in the band intensity of both peaks. In fact, ZS3 and ZS4 show a similar trend in activity. Although absorption intensity decreases in Figure 12, there is hardly any mineralization of fragmented components to $\mathrm{CO}_{2}$. Nonetheless, fragmented components can be mineralized relatively easier than the parent DCP.

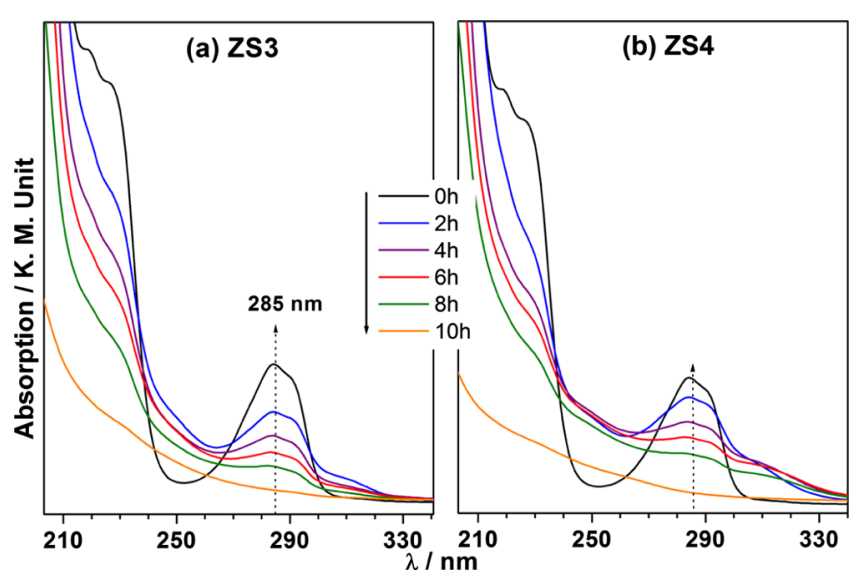

Figure 12. Absorption spectra of 2,4-DCP solution recorded at different time intervals following photodegradation with (a) ZS3 and (b) ZS4 catalyst.

The activity measurements were also carried out with all ZSx materials in direct sunlight. Necessary control experiments were also carried out. Further, a UV lamp $(\lambda=240-400 \mathrm{~nm}$; predominantly, $365 \mathrm{~nm}$ and $240-320 \mathrm{~nm})$ or $\mathrm{H}_{2} \mathrm{O}_{2}(2 \mathrm{~mL}$ of $25 \% \mathrm{H}_{2} \mathrm{O}_{2}$ in direct sunlight; see Figure S5) was employed to measure the 2,4-DCP degradation activity with ZS3. Figure 13 compares the activity of all catalysts for 2,4-DCP degradation. Control experiments, such as pure $\mathrm{ZnO}$ and $\mathrm{ZnS}$, show low activity (20-25\% degradation) in $10 \mathrm{~h}$. However, all $\mathrm{ZS} x$ catalysts show significant activity for 2,4-DCP degradation in direct sunlight. The bulk heterostructure of $\mathrm{ZS} x$ leads to absorption of visible light and shows better activity for 2,4-DCP

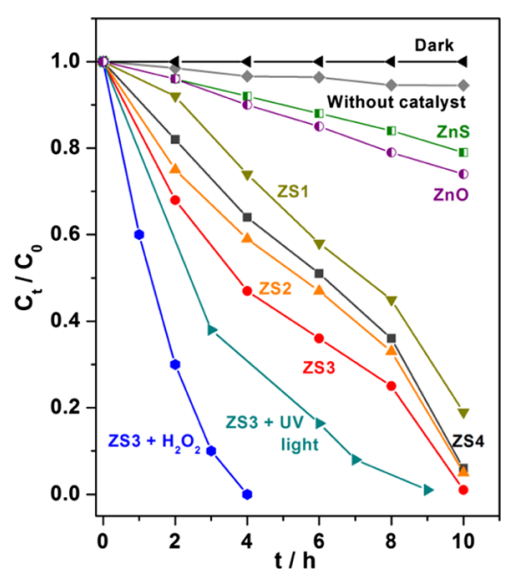

Figure 13. Photocatalytic degradation activity for 2,4-DCP with ZSx under direct sun light and UV light. 
degradation under direct sun light. The $\lambda$-max at $285 \mathrm{~nm}$ for the absorption of 2,4-DCP (Figure 12) reduced as reaction time increased. Indeed, complete 2,4-DCP degradation occurs in about $10 \mathrm{~h}$ with ZS2, ZS3, and ZS4 catalysts under direct sun light as well as in UV light irradiation. This underscores the visible light activity associated with $\mathrm{ZS} x$ materials. The activity of all other catalysts follows the order given below: ZS3 > ZS4 > ZS2 > ZS1. High surface area and pore volume in ZS3 and ZS4 adsorb a large amount of reactants on the catalyst surface; because of highly crystallinity and small particle size, the photogenerated charge carriers diffuse fast to the surface of the catalyst and react rapidly with 2,4-DCP and hence an effective utilization of charge carrier for the oxidation. ${ }^{31}$ In the presence of $\mathrm{H}_{2} \mathrm{O}_{2}$, the reaction was very fast, and 2,4-DCP degradation was completed in $3 \mathrm{~h}$. It demonstrates the formation of the hydroxyl radical from photocleavage of $\mathrm{H}_{2} \mathrm{O}_{2}$ during the light irradiation which increases the oxidation of 2,4-DCP. ${ }^{20}$ This reveals the importance of the hydroxyl radical for oxidation reaction and assists the reaction. Indeed, without a catalyst or in the absence of light, no activity was observed, which suggests that the degradation reaction occurs under a photocatalytic reaction path way. There is a finite difference in reactivity occurs between ZS3 and ZS4. ZS3 exhibits a small crystallite size $(20 \mathrm{~nm})$ with significantly high visible light absorption, which is highly required for the decomposition of ECD, whereas ZS4 shows a high crystallite size $(50 \mathrm{~nm})$ and a surface area with good necking between particles, which enhance the electron conduction and hence lead to high photocurrent generation. This underscores the necessity to have optical absorption, electrical conduction, and microstructural properties in a supplementing manner to achieve higher activity as well as photocurrent. The corresponding first-order kinetics plot and rate constant are shown in Figure S6, indicating the superior activity associated with ZS3 among $\mathrm{ZS} x$ catalysts. Indeed, either in the presence of UV light or sunlight, peroxide increases the rate constant effectively.

3.2. Photocatalytic Degradation of ES. ES is a toxic chemical and was employed as a pesticide around the globe in the past without realizing the harmful effects on human beings. Till date, an ES-infested agricultural land could not be used in many countries. ES exists as a mixture of $\alpha$ and $\beta$ isomers, and its consumption through farm products or inhalation creates genetic problems in human beings and animals. ${ }^{43}$ A small amount $(2 \mu \mathrm{g} /$ $\mathrm{mL}$ ) of ES is harmful for male fertility and affects the endocrine system. Because of harmful effects, biodegradation of ES was carried out by enzymes ${ }^{44}$ at a specific $\mathrm{pH}$. It requires several days to degrade ES into its fragments and involves several steps to grow the microorganism in a suitable environment. ${ }^{45}$ It is further limited by low degradation efficiency with high toxic metabolites, and hence a complete mineralization by cheap alternative methods, such as photocatalysis, is required. ${ }^{46}$ Thomas et al., reported photocatalytic activity studies of Ag- and $\mathrm{Au}$ incorporated $\mathrm{TiO}_{2}$ for degradation of ES under solar light irradiation. $^{46 \mathrm{~b}, \mathrm{c}}$

There are few reports on photocatalytic degradation of ES under UV light irradiation. ${ }^{46-\mathrm{e}}$ Sivagami et al. ${ }^{46 \mathrm{f}}$ studied the photocatalytic activity of $\mathrm{TiO}_{2}$ for the degradation of ES predominantly under UV light $(254 \mathrm{~nm})$. Similarly, TapiaOrozco and Vázquez employed photoactive $\mathrm{TiO}_{2}$ films for ES degradation in UV light. ${ }^{46 g}$ Very limited studies were carried out so far, and complete mineralization is yet to be realized in a sustainable manner. In the present study, photocatalytic degradation of aqueous ES was carried out under direct sun light irradiation using ZS3 and ZS4 without using any other component, such as noble metal co-catalyst or peroxide, and the results are shown in Figure 14. Decomposition of ES was

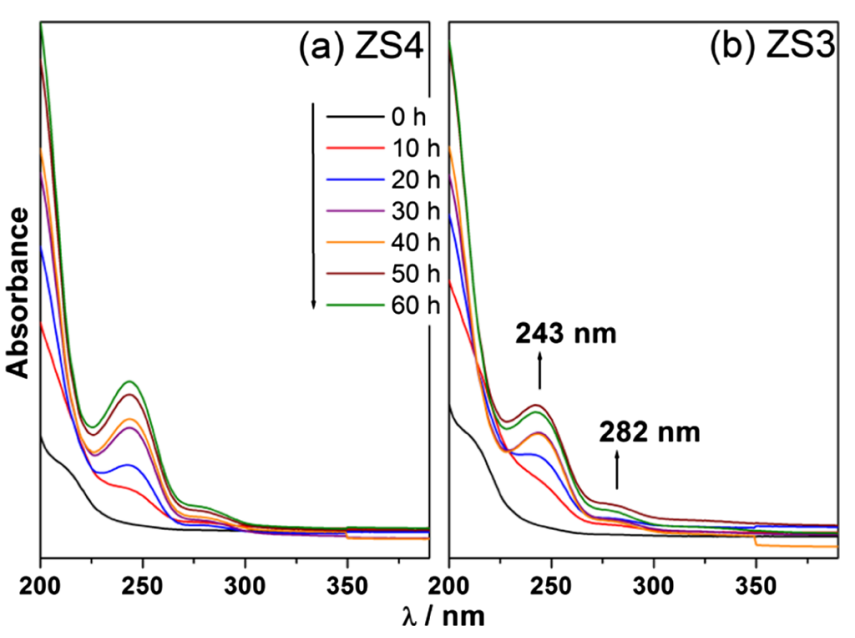

Figure 14. Absorption spectra of aqueous ES recorded at different time intervals following photodegradation with (a) ZS4 and (b) ZS3.

indicated by UV-vis absorption and confirmed by gas chromatography-mass spectrometry (GC-MS) analysis. A very similar pattern of photocatalytic degradation of ES as a function of irradiation time is shown by ZS4 (Figure 14a) and ZS3 (Figure 14b). Virgin ES shows an absorption band at 215$225 \mathrm{~nm}$ due to $\pi-\pi^{*}$ transition. However, two new absorption peaks appear at higher wavelengths as a function of direct sunlight irradiation time; new absorption peaks appeared at 243 and $282 \mathrm{~nm}$ corresponding to $\pi-\pi^{*}$ and $\mathrm{n}-\pi^{*}$ transition from one of the fragments or the decomposed product attesting the decomposition of ES into other products. The absorption feature around $200 \mathrm{~nm}$ keeps increasing with increasing illumination time, hinting the decomposition of ES into several products or small fragments, which contribute to the high intensity at 200 $\mathrm{nm}$. The absorption feature due to ES at $215 \mathrm{~nm}$ disappears gradually. This observation demonstrates the formation of a new product increased with irradiation time. Nonetheless, it was not possible to confirm the complete degradation of ES and the nature of fragments or products because of decomposition from absorption spectral studies. To explore more on this aspect, GCMS analysis was carried out for pure ES and products or fragments that remain in solution after $60 \mathrm{~h}$ of continuous solar irradiation over eight days with the ZS4 catalyst.

GC-MS analysis shows two isomer peaks of ES $\alpha$ and $\beta$ at retention times $\left(R_{t}\right) 16.4$ and $17.6 \mathrm{~min}$, as shown in Figure 15a (and Figure S7a). Corresponding mass spectra for ES $\alpha$ and $\beta$ are given in Figure $S 7 \mathrm{~b}, \mathrm{c}$. After $60 \mathrm{~h}$ of sunlight irradiation, no peak corresponding to $\alpha$ and $\beta$ ES was observed in GC (Figure 15b); however, many new features are observed, which is attributed to the various fragments from the decomposition of ES, and the corresponding mass spectrum of each new fragment is given in Figure S8 (1-10). All possible products are listed in Table S1. $R_{t}$ $=3.378 \mathrm{~min}$ (Figure S8-1) shows mass fragmentations at $\mathrm{m} / z$ $118\left(\mathrm{C}_{9} \mathrm{H}_{10}^{+}\right), 103\left(\mathrm{C}_{8} \mathrm{H}_{7}^{+}\right), 91\left(\mathrm{C}_{7} \mathrm{H}_{7}^{+}\right), 77\left(\mathrm{C}_{6} \mathrm{H}_{5}^{+}\right), 44$ $\left(\mathrm{C}_{2} \mathrm{H}_{4} \mathrm{O}^{+}\right)$, and $32\left(\mathrm{CH}_{4} \mathrm{O}^{+}\right)$; chemical composition of this fragment is $\mathrm{C}_{10} \mathrm{H}_{12} \mathrm{O}$, and the probability for the same is $97.9 \%$. Figure S8-2 shows a typical mass fragmentation of $\alpha$ methylbenzyl alcohol from the feature at $R_{t}=4.128 \mathrm{~min}$; the relative mass fragmentation observed at $m / z$ s $122\left(\mathrm{M}^{+}=\right.$ $\left.\mathrm{C}_{8} \mathrm{H}_{10} \mathrm{O}^{+}\right), 120\left(\mathrm{C}_{8} \mathrm{H}_{8} \mathrm{O}^{+}\right), 107\left(\mathrm{M}^{+}-\mathrm{CH}_{3}\right), 105\left(\mathrm{C}_{7} \mathrm{H}_{5} \mathrm{O}^{+}\right), 79$ 


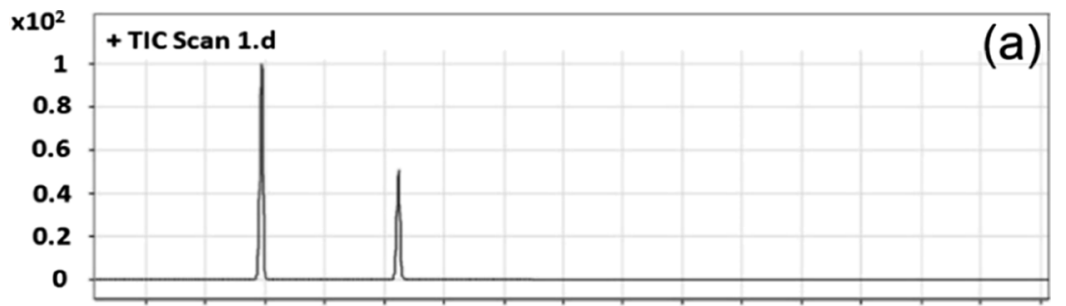

$\begin{array}{llllllllllllllll}15.5 & 16 & 16.5 & 17 & 17.5 & 18 & 18.5 & 19 & 19.5 & 20 & 20.5 & 21 & 21.5 & 22 & 22.5\end{array}$

Counts vs. Acquisition Time (min)

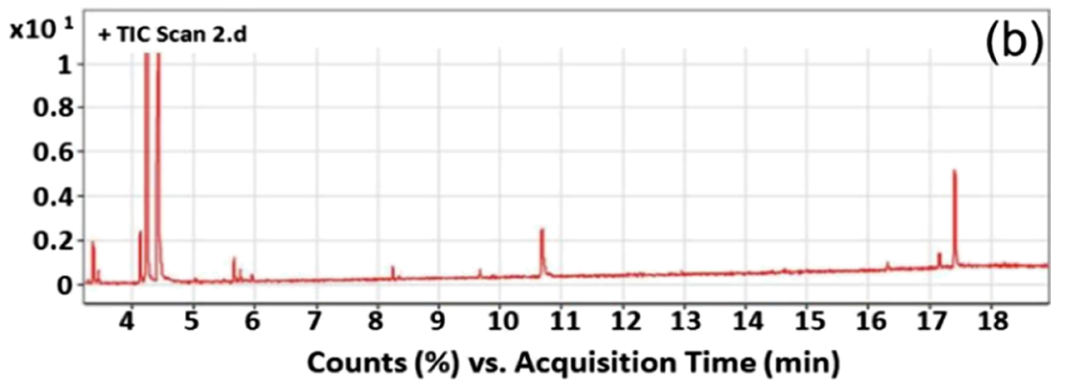

Figure 15. GC results obtained for (a) ES and (b) ES fragments after $60 \mathrm{~h}$ of irradiation under direct sunlight with a ZS4 catalyst. Corresponding mass spectral patterns and identity are given in Figure S8 and Table S1, respectively.

$\left(\mathrm{C}_{6} \mathrm{H}_{7}^{+}\right), 77\left(\mathrm{C}_{6} \mathrm{H}_{5}^{+}\right)$, and $44\left(\mathrm{C}_{2} \mathrm{H}_{4} \mathrm{O}^{+}\right)$supports this. It is wellstudied that benzene derivatives give a phenylium ion peak at $m$ / $z 77$ and observed that the probability of $\alpha$-methylbenzyl alcohol is $50.1 \%$ by the NIST library. ${ }^{45}$ Figure S8-3 shows the MS corresponding to $R_{t}=4.225 \mathrm{~min}$, and it exactly matches with the $m / z$ patterns of acetophenone with a probability of $70 \% .{ }^{45}$ The observed mass fragments are $m / z=120\left(\mathrm{M}^{+}\right), 105(\mathrm{M}-$ $\left.\mathrm{CH}_{3} \mathrm{CO}^{+} ; \mathrm{C}_{7} \mathrm{H}_{5} \mathrm{O}^{+}\right), 77\left(\mathrm{C}_{6} \mathrm{H}_{5}^{+}\right)$, and $43\left(\mathrm{CH}_{3} \mathrm{CO}^{+}\right)$. The mass spectrum of the next feature that appeared at $R_{t}=4.42 \mathrm{~min}$ (Figure S8-4) matches with that of 2-phenyl-2-propenol with a probability of $92 \%$; this feature shows a parent peak at $m / z 136$ $\left(\mathrm{M}^{+}=\mathrm{C}_{9} \mathrm{H}_{12} \mathrm{O}^{+}\right)$, and the following fragment peaks appeared at $\left.m / z 121\left(\mathrm{M}^{+}-\mathrm{CH}_{3}\right), 118 \mathrm{M}^{+}-\mathrm{H}_{2} \mathrm{O}\right), 103\left(\mathrm{C}_{8} \mathrm{H}_{7}^{+}\right), 91\left(\mathrm{C}_{7} \mathrm{H}_{8}^{+}\right)$, $77\left(\mathrm{C}_{6} \mathrm{H}_{5}^{+}\right)$, and $43\left(\mathrm{CH}_{3} \mathrm{CO}^{+}\right)$. Last two features are the major products observed in the GC pattern because of ES degradation. Observation of these products attests dechlorination of ES in the first step followed by formation of acetophenone or 2-phenyl-2propenol. Indeed, this is an important observation because dechlorination of ES makes the resulting products to a simple organic molecule that can be photocatalytically degraded easily. Further, it removes the harmful nature that leads to endocrine disruption.

A minor feature observed at $R_{t}=5.65 \mathrm{~min}$ can be attributed to octanol from the mass spectrum (Figure S8-5) with a chemical composition of $\mathrm{M}^{+}=\mathrm{C}_{8} \mathrm{H}_{18} \mathrm{O}^{+}$exhibiting major mass fragments at $m / z 111\left(\mathrm{C}_{8} \mathrm{H}_{15}{ }^{+}\right), 97\left(\mathrm{C}_{7} \mathrm{H}_{13}{ }^{+}\right), 83\left(\mathrm{C}_{6} \mathrm{H}_{11}{ }^{+}\right), 69\left(\mathrm{C}_{5} \mathrm{H}_{9}^{+}\right), 55$ $\left(\mathrm{C}_{4} \mathrm{H}_{7}^{+}\right), 44\left(\mathrm{C}_{3} \mathrm{H}_{8}^{+}\right)$, and $32\left(\mathrm{CH}_{4} \mathrm{O}^{+}\right)$. Another minor feature at $R_{t}=8.2 \mathrm{~min}$ shows mass fragments (Figure S8-6) at $\mathrm{m} / z 111$ $\left(\mathrm{C}_{8} \mathrm{H}_{15}{ }^{+}\right), 97\left(\mathrm{C}_{7} \mathrm{H}_{13}{ }^{+}\right), 83\left(\mathrm{C}_{6} \mathrm{H}_{11}^{+}\right), 69\left(\mathrm{C}_{5} \mathrm{H}_{9}^{+}\right), 55\left(\mathrm{C}_{4} \mathrm{H}_{7}^{+}\right)$, $44\left(\mathrm{C}_{3} \mathrm{H}_{8}^{+}\right)$, and $32\left(\mathrm{CH}_{3} \mathrm{OH}^{+}\right.$is likely due to adduct formation with methanol used as a reaction solvent). Yet another minor feature at $R_{t}=9.6 \mathrm{~min}$ (Figure S8-7) predicted to be a norbornadiene derivative with chemical composition $\mathrm{C}_{8} \mathrm{H}_{7} \mathrm{Cl}_{3}$ $\left(\mathrm{M}^{+}=208\right)$ exhibiting mass fragmentations at $206\left(\mathrm{M}^{+}-2\right), 191$ $\left(\mathrm{C}_{7} \mathrm{H}_{2} \mathrm{Cl}_{3}\right), 91\left(\mathrm{C}_{7} \mathrm{H}_{7}^{+}\right), 44\left(\mathrm{C}_{3} \mathrm{H}_{8}^{+}\right), 40$, and 32. A partially dechlorinated product from ES leads to norbornadiene; very low intensity highlights the fast decomposition of them as well as fast dechlorination as a whole. A fragment observed at $R_{t}=10.7 \mathrm{~min}$ (Figure S8-8) is attributed to diethyl phthalate, as the observed MS pattern is in good agreement with that. ${ }^{47}$
A feature observed at $R_{t}=17.15$ min shows mass fragments at $307\left(\mathrm{C}_{9} \mathrm{H}_{6} \mathrm{Cl} 5 \mathrm{O}\right), 207\left(\mathrm{C}_{8} \mathrm{H}_{6} \mathrm{Cl}_{3}^{+}\right), 44\left(\mathrm{C}_{2} \mathrm{H}_{4} \mathrm{O}^{+}\right)$, and 32 $\left(\mathrm{CH}_{4} \mathrm{O}^{+}\right)$(Figure S8-9); from the above mentioned fragments, it has been predicted that the parent chemical composition is $\mathrm{C}_{9} \mathrm{H}_{6} \mathrm{Cl}_{6} \mathrm{O}\left(\mathrm{M}^{+}=342\right)$, and it is likely to be $\mathrm{ES}-$ ether. GC results show a peak at $R_{t}=17.4 \mathrm{~min}$ (Figures S8-10), and the corresponding MS results show a typical MS pattern of ES-diol; $\mathrm{C}_{9} \mathrm{H}_{8} \mathrm{Cl}_{6} \mathrm{O}_{2}$ with a molecular mass of 360 with a probability of 84.7\%. The corresponding mass values appeared at $\mathrm{m} / z 325$ $\left(\mathrm{C}_{9} \mathrm{H}_{8} \mathrm{Cl}_{5}^{+} \mathrm{O}_{2}\right), 307\left(\mathrm{C}_{9} \mathrm{H}_{4} \mathrm{Cl}_{5}^{+}\right), 277\left(\mathrm{C}_{8} \mathrm{H}_{8} \mathrm{Cl}_{3}\right), 207$ $\left(\mathrm{C}_{8} \mathrm{H}_{6} \mathrm{Cl}_{2} \mathrm{O}_{2}^{+}\right), 170\left(\mathrm{C}_{8} \mathrm{H}_{5} \mathrm{ClO}_{2}^{+}\right), 44\left(\mathrm{C}_{2} \mathrm{H}_{4} \mathrm{O}^{+}\right)$, and 32 $\left(\mathrm{CH}_{4} \mathrm{O}^{+}\right)$. Other unidentified products (trace amounts) were also observed on GC-MS. The above mentioned discussions are consistent with the UV-visible absorption spectrum of degraded products; the observed peaks at 243 and $282 \mathrm{~nm}$ correspond to $\pi-\pi^{*}$ and $n-\pi^{*}$ transitions of benzene derivatives attached with heteroatoms such as $-\mathrm{OH}$ or keto groups. From the GC-MS and UV-visible results, it demonstrates that ES was degraded through ES-diol, ES-ether, $\alpha$-methylbenzyl alcohol, and acetophenone pathway; it was further degraded into smaller fragments. Importantly, the above mentioned observations highlight the visible light activity associated with $\mathrm{ZS} x$ catalysts. Indeed, without a catalyst or in the absence of light source, no ES degradation was observed. A semiquantitative calculation from the GC chromatogram recorded before and after the $60 \mathrm{~h}$ irradiation demonstrates that, at least $80 \%$ ES was completely mineralized to $\mathrm{CO}_{2}$ through various fragments. Some of the corollary experiments carried out for complete degradation of acetophenone or 2-phenyl-2-propanol with ZS4 (not shown) in sunlight occurs in 16-20 h with $50 \mathrm{ppm}$ concentration.

$\mathrm{ZnO}-\mathrm{ZnS}$ heterojunctions present in $\mathrm{ZS} x$ is the prime reason for the visible light absorption and better activity. The heterojunctions observed between $\mathrm{ZnS}$ and $\mathrm{ZnO}$ nanocrystallites help in electron-hole pair separation, and facile mobility of charge carriers allows for better photocatalytic degradation of ES. The porous structure and high surface area induce the photogenerated carriers to diffuse fast to the surface and react rapidly with the adsorbed molecules and hence an effective utilization of charge carriers for the degradation of ES. 


\section{CONCLUSION}

$\mathrm{ZnO}-\mathrm{ZnS}(\mathrm{ZS} x)$ composites with heterojunctions between the constituent components were prepared by the SCM and characterized by a variety of physicochemical, spectral, and microscopy measurements. ZS $x$ were indexed to the wurtzite structure; however, with an increase in the thiourea amount, an increase in the $\mathrm{ZnS}$ content was also observed. An important point to be noted is the increasing crystallite size of $\mathrm{ZnS}$ with increasing thiourea content in the reactant mixture. Heat treatment in air between 450 and $650{ }^{\circ} \mathrm{C}$ decreases the $\mathrm{ZnS}$ crystallite size, offering a method to fine tune the particle size. The present method of preparation and the tuning of the $\mathrm{ZnS}$ crystallite size in the solid state are important, and it is not available at present in the solid state. Further, high thermal stability of the present materials makes them flexible for several applications, including catalysis.

The porous structure with needle- or V-shaped particles with significant macropore contribution underscores its potential in sensing and catalysis applications. Raman, SIMS, TG, and XRD studies demonstrate the direct bonding between $\mathrm{Zn}$ and $\mathrm{S}$ as in typical ZnS. Optical absorption studies demonstrate a significant decrease in the band gap down to $2.3 \mathrm{eV}$ for $\mathrm{ZS} x$ compared to wide band gap for parent materials $(\mathrm{ZnO}-\mathrm{ZnS})$. The band gap diminution of $\mathrm{ZS} x$ has been attributed to the formation of hybrid orbitals in the VB and CB. It is expected that $S 3 p$ and $O 2 p$ are likely to overlap in the VB of ZSx at and around interfaces and heterojunctions, and the extent of overlap increases from ZS1 to ZS4. Sulphur exists as an $\mathrm{S}^{2-}$ anion in ZSx, and the top of the VB might be predominantly composed of $S 3 p$ bands, as they have higher orbital energies than O $2 p$ levels. Thus, $S 3 p$ and O $2 p$ bands overlap and broaden the VB compared to $\mathrm{ZnO}$ or $\mathrm{ZnS}$. The above mentioned studies affirm the nature of $\mathrm{ZS} x$ with heterojunctions between $\mathrm{ZnO}$ and $\mathrm{ZnS}$ and $\mathrm{ZS} x$ as a potential candidate for PV application.

Photocurrent generation under 1 sun condition and heterojunctions observed between $\mathrm{ZnO}$ and $\mathrm{ZnS}$ demonstrates the effective sunlight absorption and separation of charge carriers. Probably, this is the first report to demonstrate photocurrent generation under 1 sun condition by combining two wide band gap semiconductors into a composite with heterojunctions. Photocatalytic activity studies of $\mathrm{ZS} x$ (for complete mineralization of 2,4-DCP and ES ECDs in direct sunlight) demonstrate its potential to develop efficient visible light active photocatalysts. We also suggest that $\mathrm{ZS} x$ composites might offer a possible solution to eradicate the EDC contamination in the large amount of farm lands in many countries. A simple mixing of ZS $x$ with the soil in the presence of water and sunlight would mineralize EDC in about a month's time, and it is very likely to make the land cultivable again. However, systematic and thorough pilot plant studies will be required to evaluate the feasibility of this option. These applications are depicted pictorially in Figure 16.

\section{EXPERIMENTAL SECTION}

5.1. Synthesis of $\mathrm{ZnO}-\mathrm{ZnS}$ Composites. All chemicals employed were of analytical grade and used as such. $\mathrm{Zn}\left(\mathrm{NO}_{3}\right)_{2}$. $6 \mathrm{H}_{2} \mathrm{O}$ (Merck) as a zinc precursor and urea and thiourea (Loba Chemie) as fuels were used. $\mathrm{SCM}^{30}$ was adopted to make $\mathrm{ZS} x$, which is a simple process that requires short time and a laboratory furnace. In a typical synthesis procedure, an equimolar (0.04 mol) amount $\mathrm{Zn}\left(\mathrm{NO}_{3}\right)_{2} \cdot 6 \mathrm{H}_{2} \mathrm{O}$ and fuel, (but with a different ratio of urea and thiourea, varied from $100 \%$ urea to

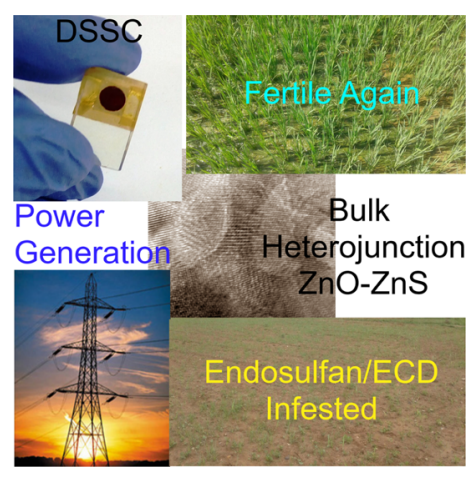

Figure 16. Possible applications with $\mathrm{ZS} x$ composites are depicted. (Right) ES-/ECD-infested land could be made fertile again and (left) possible to generate power. Both applications are with direct sunlight.

$100 \%$ thiourea) were taken in a $250 \mathrm{~mL}$ beaker with $10 \mathrm{~mL}$ of distilled water.

After thorough solubilization of reactants, the solution was introduced into a preheated furnace at $500{ }^{\circ} \mathrm{C}$. Water evaporation takes place for up to $2 \mathrm{~min}$, followed by ignition of the reactant mixture, yielding a yellow solid. With $100 \%$ urea, brown-colored $\mathrm{ZnO}_{1-x} \mathrm{~N}_{x}$ was obtained. ${ }^{16}$ The solid product was collected after the completion of the combustion process. Urea/ thiourea was varied from 100:0, 75:25, 50:50, and 25:75 to 0:100, and the resulting materials are designated as Z1, ZS1, ZS2, ZS3, and ZS4, respectively. All the above mentioned materials were thoroughly characterized, and the characterization methods and instruments are described in the Supporting Information (S1).

\section{ASSOCIATED CONTENT}

\section{S Supporting Information}

The Supporting Information is available free of charge on the ACS Publications website at DOI: 10.1021/acsomega.7b01172.

Characterization and instrument methods (S1), XRD (Figure S1), EDX (Figure S2), X-ray photoelectron spectroscopy (Figure S3), IPCE results (Figure S4), 2,4DCP degradation spectral results with ZSx (Figure S5), 2,4-DCP degradation kinetics details (Figure S6), GCMS results of endosulfan (Figure S7), degradation fragments (Figure S8), and a list of mass fragments and assignments (Table S1) (PDF)

\section{AUTHOR INFORMATION}

\section{Corresponding Author}

*E-mail: cs.gopinath@ncl.res.in. Phone: 009-20-25902043. Fax: (+91) 20-2590-2633.

ORCID 8

Kothandam Krishnamoorthy: 0000-0003-0603-8694

Chinnakonda S. Gopinath: 0000-0002-4525-3912

\section{Author Contributions}

P.D. and M.M. equal first authors.

Notes

The authors declare no competing financial interest.

\section{ACKNOWLEDGMENTS}

We thank Prof. P. Chakraborty, SINP, Kolkata, for careful SIMS measurements and Dr. E. Balaraman for helping in GC-MS interpretation. P.D. thanks UGC for research fellowship. We thank CSIR, New Delhi, for financial support through NWP0056. 


\section{REFERENCES}

(1) Kudo, A.; Miseki, Y. Heterogeneous photocatalyst materials for water splitting. Chem. Soc. Rev. 2009, 38, 253-278.

(2) (a) Peng, Y.-K.; Ye, L.; Qu, J.; Zhang, L.; Fu, Y.; Teixeira, I. F.; McPherson, I. J.; He, H.; Tsang, S. C. E. Trimethylphosphine Assisted Surface Fingerprinting of Metal Oxide Nanoparticle by 31P Solid-State NMR: A Zinc Oxide Case Study. J. Am. Chem. Soc. 2016, 138, 22252234. (b) Takayama, T.; Iwase, A.; Kudo, A. Photocatalytic water splitting and $\mathrm{CO}_{2}$ reduction over $\mathrm{KCaSrTa}_{5} \mathrm{O}_{15}$ naorod prepared by a polymerized complex method. Bull. Chem. Soc. Jpn. 2015, 88, 538-543.

(3) (a) Maeda, K.; Domen, K. Development of novel photocatalyst and cocatalyst materials for water splitting under visible light. Bull. Chem. Soc. Jpn. 2016, 89, 627-648. (b) Fang, X.; Bando, Y.; Gautam, U. K.; Ye, C.; Golberg, D. Inorganic semiconductor nanostructures and their fieldemission applications. J. Mater. Chem. 2008, 18, 509-522.

(4) Hu, J.-S.; Ren, L.-L.; Guo, Y.-G.; Liang, H.-P.; Cao, A.-M.; Wan, L.J.; Bai, C.-L. Mass Production and High Photocatalytic Activity of $\mathrm{ZnS}$ Nanoporous Nanoparticles. Angew. Chem. 2005, 117, 1295-1299.

(5) Ullattil, S. G.; Periyat, P.; Naufal, B.; Lazar, M. A. Self-Doped ZnO Microrods-High Temperature Stable Oxygen Deficient Platforms for Solar Photocatalysis. Ind. Eng. Chem. Res. 2016, 55, 6413-6421.

(6) Chou, T. P.; Zhang, Q.; Cao, G. Effects of Dye Loading Condtions on the Energy Conversion Efficiency of $\mathrm{ZnO}$ and $\mathrm{TiO}_{2}$ Dye-Sensitized Solar Cells. J. Phys. Chem. C 2007, 111, 18804-18811.

(7) Sakthivel, S.; Neppolian, B.; Shankar, M. V.; Arabindoo, B.; Palanichamy, M.; Murugesan, V. Solar photocatalytic degradation of azo dye: comparison of photocatalytic efficiency of $\mathrm{ZnO}$ and $\mathrm{TiO} 2$. Sol. Energy Mater. Sol. Cells 2003, 77, 65-82.

(8) Yang, J. L.; An, S. J.; Park, W. I.; Yi, G.-C.; Choi, W. Photocatalysis Using ZnO Thin Films and Nanoneedles Grown by Metal-Organic Chemical Vapor Deposition. Adv. Mater. 2004, 16, 1661-1664.

(9) Mohan, M.; Nandal, V.; Paramadam, S.; Reddy, K. P.; Ramkumar, S.; Agarwal, S.; Gopinath, C. S.; Nair, P. R.; Namboothiry, M. A. G. Efficient organic photovoltaics with improved charge extraction and high short circuit current. J. Phys. Chem. C 2017, 121, 5523-5530.

(10) Park, W.; King, J. S.; Neff, C. W.; Liddell, C.; Summers, C. J. ZnSBased Photonic Crystals. Phys. Status Solidi B 2002, 229, 949-960.

(11) Nanda, J.; Sapra, S.; Sarma, D. D.; Chandrasekharan, N.; Hodes, G. Size-Selected Zinc Sulfide Nanocrystallites: Synthesis, Structure, and Optical Studies. Chem. Mater. 2000, 12, 1018-1024.

(12) Yu, S.-H.; Yoshimura, M. Shape and Phase Control of ZnS Nanocrystals: Template Fabrication of Wurtzite ZnS Single-Crystal Nanosheets and $\mathrm{ZnO}$ Flake-like Dendrites from a Lamellar Molecular Precursor ZnS. $\left(\mathrm{NH}_{2} \mathrm{CH}_{2} \mathrm{CH}_{2} \mathrm{NH}_{2}\right)_{0.5}$. Adv. Mater. 2002, 14, 296-300.

(13) (a) Chen, C. C.; Herhold, A. B.; Johnson, C. S.; Alivisatos, A. P. Size Dependence of Structural Metastability in Semiconductor Nanocrystals. Science 1997, 276, 398-401. (b) Schrier, J.; Demchenko, D. O.; Wang, L.; Alivisatos, A. P. Optical Properties of $\mathrm{ZnO} / \mathrm{ZnS}$ and $\mathrm{ZnO} / \mathrm{ZnTe}$ Heterostructures for Photovoltaic Applications. Nano Lett. 2007, 7, 2377-2382.

(14) (a) Hensel, J.; Wang, G.; Li, Y.; Zhang, J. Z. Synergistic Effect of CdSe Quantum Dot Sensitization and Nitrogen Doping of $\mathrm{TiO}_{2}$ Nanostructures for Photoelectrochemical Solar Hydrogen Generation. Nano Lett. 2010, 10, 478-483. (b) Lee, Y.-L.; Chi, C.-F.; Liau, S.-Y. $\mathrm{CdS} / \mathrm{CdSe}$ Co-Sensitized $\mathrm{TiO}_{2}$ Photoelectrode for Efficient Hydrogen Generation in a Photoelectrochemical Cell. Chem. Mater. 2010, 22, 922-927.

(15) Patil, A. B.; Patil, K. R.; Pardeshi, S. K. Ecofriendly synthesis and solar photocatalytic activity of S-doped ZnO. J. Hazard. Mater. 2010, $183,315-323$.

(16) Mapa, M.; Gopinath, C. S. Combustion Synthesis of Triangular and Multifunctional $\mathrm{ZnO}_{1-x} \mathrm{~N}_{x}(x \leq 0.15)$ Materials. Chem. Mater. 2009, 21, 351-359.

(17) Chen, L.-C.; Tu, Y.-J.; Wang, Y.-S.; Kan, R.-S.; Huang, C.-M. Characterization and photoreactivity of $\mathrm{N}$-, $\mathrm{S}$-, and $\mathrm{C}$-doped $\mathrm{ZnO}$ under UV and visible light illumination. J. Photochem. Photobiol., A 2008, 199, $170-178$.

(18) (a) Shen, G.; Cho, J. H.; Yoo, J. K.; Yi, G.-C.; Lee, C. J. Synthesis and Optical Properties of S-Doped ZnO Nanostructures: Nanonails and
Nanowires. J. Phys. Chem. B 2005, 109, 5491-5496. (b) Bald, L.; Gruehn, R. Die Kristallstruktur von einem Sulfat-reichen Oxidsulfat des Zinks. Naturwissenschaften 1981, 68, 39.

(19) Naik, B.; Parida, K. M.; Gopinath, C. S. Facile Synthesis of N- and S-Incorporated Nanocrystalline $\mathrm{TiO}_{2}$ and Direct Solar-Light-Driven Photocatalytic Activity. J. Phys. Chem. C 2010, 114, 19473-19482.

(20) (a) Devaraji, P.; Sathu, N. K.; Gopinath, C. S. Ambient Oxidation of Benzene to Phenol by Photocatalysis on $\mathrm{Au} / \mathrm{Ti}_{0.98} \mathrm{~V}_{0.02} \mathrm{O}_{2}$ : Role of Holes. ACS Catal. 2014, 4, 2844-2853. (b) Satish, M.; Viswanathan, B.; Viswanath, R. P.; Gopinath, C. S. Synthesis, Characterization, Electronic Structure, and Photocatalytic Activity of Nitrogen-Doped $\mathrm{TiO}_{2}$ Nanocatalyst. Chem. Mater. 2005, 17, 6349-6353. (c) Gopinath, C. S. Comment on "Photoelectron Spectroscopic Investigation of NitrogenDoped Titania Nanoparticles". J. Phys. Chem. B 2006, 110, 7079-7080.

(21) Fabbri, F.; Nasi, L.; Fedeli, P.; Ferro, P.; Salviati, G.; Mosca, R.; Calzolari, A.; Catellani, A. S-induced modifications of the optoelectronic properties of $\mathrm{ZnO}$ mesoporous nanobelts. Sci. Rep. 2016, 6, 27948.

(22) (a) Ohno, T.; Akiyoshi, M.; Umebayashi, T.; Asai, K.; Mitsui, T.; Matsumura, M. Preparation of S-doped $\mathrm{TiO}_{2}$ photocatalysts and their photocatalytic activities under visible light. Appl. Catal., A 2004, 265, 115-121. (b) Geng, B. Y.; Wang, G. Z.; Jiang, Z.; Xie, T.; Sun, S. H.; Meng, G. W.; Zhang, L. D. Synthesis and optical properties of S-doped $\mathrm{ZnO}$ nanowires. Appl. Phys. Lett. 2003, 82, 4791-4793.

(23) Xiong, G.; Wilkinson, J.; Mischuck, B.; Tüzemen, S.; Ucer, K. B.; Williams, R. T. Control of p- and n-type conductivity in sputter deposition of undoped ZnO. Appl. Phys. Lett. 2002, 80, 1195-1197.

(24) Perkins, C. L.; Lee, S.-H.; Li, X.; Asher, S. E.; Coutts, T. J. Identification of nitrogen chemical states in $\mathrm{N}$-doped $\mathrm{ZnO}$ via $\mathrm{x}$-ray photoelectron spectroscopy. J. Appl. Phys. 2005, 97, 034907.

(25) Wang, C.-y.; Bahnemann, D. W.; Dohrmann, J. K. A novel preparation of iron-doped $\mathrm{TiO}_{2}$ nanoparticles with enhanced photocatalytic activity. Chem. Commun. 2000, 1539-1540.

(26) (a) Mapa, M.; Thushara, K. S.; Saha, B.; Chakraborty, P.; Janet, C. M.; Viswanath, R. P.; Nair, C. M.; Murty, K. V. G. K.; Gopinath, C. S. Electronic Structure and Catalytic Study of Solid Solution of GaN in ZnO. Chem. Mater. 2009, 21, 2973-2979. (b) RajaAmbal, S.; Yadav, A. K.; Jha, S. N.; Bhattacharyya, D.; Gopinath, C. S. Electronic structuresunlight driven water splitting activity correlation of $\left(\mathrm{Zn}_{1-\mathrm{y}} \mathrm{Ga}_{\mathrm{y}}\right)$ $\left(\mathrm{O}_{1-2} \mathrm{~N}_{\mathrm{z}}\right)$. Phys. Chem. Chem. Phys. 2014, 16, 23654-23662.

(27) Rajaambal, S.; Mapa, M.; Gopinath, C. S. In1-xGaxN@ZnO: a rationally designed and quantum dot integrated material for water splitting and solar harvesting applications. Dalton Trans. 2014, 43, 12546-12554.

(28) (a) Maeda, K.; Domen, K. New Non-Oxide Photocatalysts Designed for Overall Water Splitting under Visible Light. J. Phys. Chem. C 2007, 111, 7851-7861. (b) Maeda, K.; Takata, T.; Hara, M.; Saito, N.; Inoue, Y.; Kobayashi, H.; Domen, K. GaN:ZnO Solid Solution as a Photocatalyst for Visible-Light-Driven Overall Water Splitting. J. Am. Chem. Soc. 2005, 127, 8286-8287.

(29) Sivaranjani, K.; Gopinath, C. S. Porosity driven photocatalytic activity of wormhole mesoporous $\mathrm{TiO}_{2-\mathrm{x}} \mathrm{N}_{\mathrm{x}}$ in direct sunlight. J. Mater. Chem. 2011, 21, 2639-2647.

(30) Mapa, M.; Sivaranjani, K.; Bhange, D. S.; Saha, B.; Chakraborty, P.; Viswanath, A. K.; Gopinath, C. S. Structure, Electronic Structure, Optical, and Dehydrogenation Catalytic Study of $\left(\mathrm{Zn}_{1-\mathrm{z}} \mathrm{In}_{\mathrm{z}}\right)\left(\mathrm{O}_{1-\mathrm{x}} \mathrm{N}_{\mathrm{x}}\right)$ Solid Solution. Chem. Mater. 2010, 22, 565-578.

(31) Foreman, J. V.; Li, J.; Peng, H.; Choi, S.; Everitt, H. O.; Liu, J. Time-Resolved Investigation of Bright Visible Wavelength Luminescence from Sulfur-Doped $\mathrm{ZnO}$ Nanowires and Micropowders. Nano Lett. 2006, 6, 1126-1130.

(32) Sivaranjani, K.; Agarkar, S.; Ogale, S. B.; Gopinath, C. S. Toward a Quantitative Correlation between Microstructure and DSSC Efficiency: A Case Study of $\mathrm{TiO}_{2-\mathrm{x}} \mathrm{N}_{\mathrm{x}}$ Nanoparticles in a Disordered Mesoporous Framework. J. Phys. Chem. C 2012, 116, 2581-2587.

(33) Kulkarni, D. G.; Murugan, A. V.; Viswanath, A. K.; Gopinath, C. S. Template Free Synthesis of Mesoporous $\mathrm{TiO}_{2}$ with High Wall Thickness in Nanocrystalline Framework. J. Nanosci. Nanotechnol. 2009, 9, 371-377. 
(34) Sivaranjani, K.; RajaAmbal, S.; Das, T.; Roy, K.; Bhattacharyya, S.; Gopinath, C. S. Disordered Mesoporous $\mathrm{TiO}_{2-\mathrm{x}} \mathrm{N}_{\mathrm{x}}+\mathrm{Nano}-\mathrm{Au}$ : $\mathrm{An}$ Electronically Integrated Nanocomposite for Solar $\mathrm{H}_{2}$ Generation. ChemCatChem 2014, 6, 522-530.

(35) Rajaambal, S.; Sivaranjani, K.; Gopinath, C. S. Recent developments in solar $\mathrm{H}_{2}$ generation from water splitting. J. Chem. Sci. 2015, $127,33-47$.

(36) (a) Melvin, A. A.; Illath, K.; Das, T.; Raja, T.; Bhattacharyya, S.; Gopinath, C. S. M-Au/TiO2 ( $\mathrm{M}=\mathrm{Ag}, \mathrm{Pd}$, and $\mathrm{Pt})$ nanophotocatalyst for overall solar water splitting: role of interfaces. Nanoscale 2015, 7, 13477-13488. (b) Patra, K. K.; Gopinath, C. S. Bimetallic and Plasmonic $\mathrm{Ag}-\mathrm{Au}$ on $\mathrm{TiO} 2$ for Solar Water Splitting: An Active Nanocomposite for Entire Visible-Light-Region Absorption. ChemCatChem 2016, 8, 3294-3311. (c) Patra, K. K.; Bhuskute, B. D.; Gopinath, C. S. Possibly scalable solar hydrogen generation with quasiartificial leaf approach. Sci. Rep. 2017, 7, 6516.

(37) Bharad, P. A.; Sivaranjani, K.; Gopinath, C. S. A rational approach towards enhancing solar water splitting: a case study of $\mathrm{Au}-\mathrm{RGO} / \mathrm{N}$ RGO-TiO ${ }_{2}$. Nanoscale 2015, 7, 11206-11215.

(38) (a) Murugan, B.; Ramaswamy, A. V.; Srinivas, D.; Gopinath, C. S.; Ramaswamy, V. Nature of Manganese Species in $\mathrm{Ce}_{1-\mathrm{x}} \mathrm{Mn}_{\mathrm{x}} \mathrm{O}_{2-\delta}$ Solid Solutions Synthesized by the Solution Combustion Route. Chem. Mater. 2005, 17, 3983. (b) Murugan, B.; Ramaswamy, A. V.; Srinivas, D.; Gopinath, C. S.; Ramaswamy, V. Effect of fuel and its concentration on the nature of $\mathrm{Mn}$ in $\mathrm{Mn} / \mathrm{CeO}_{2}$ solid solutions prepared by solution combustion synthesis. Acta Mater. 2008, 56, 1461-1472.

(39) (a) Kaschner, A.; Haboeck, U.; Strassburg, M.; Strassburg, M.; Kaczmarczyk, G.; Hoffmann, A.; Thomsen, C.; Zeuner, A.; Alves, H. R.; Hofmann, D. M.; Meyer, B. K. Nitrogen-related local vibrational modes in ZnO:N. Appl. Phys. Lett. 2002, 80, 1909-1911. (b) Yu, J.; Xing, H.; Zhao, Q.; Mao, H.; Shen, Y.; Wang, J.; Lai, Z.; Zhu, Z. The origin of additional modes in Raman spectra of $\mathrm{N}^{+}$-implanted $\mathrm{ZnO}$. Solid State Commun. 2006, 138, 502-504.

(40) Chakraborty, P. Ion Beam Analysis of Surfaces and Interfaces in Condensed Matter Systems; Nova Science Publishers: New York, 2002.

(41) Wang, Q.; Moser, J.-E.; Grätzel, M. Electrochemical Impedance Spectroscopic Analysis of Dye-Sensitized solar Cells. J. Phys. Chem. B 2005, 109, 14945-14953.

(42) Benfeito, S.; Silva, T.; Garrido, J.; Andrade, P. B.; Sottomayor, M. J.; Borges, F.; Garrido, E. M. Effects of Chlorophenoxy Herbicides and Their Main Transformation Products on DNA Damage and Acetylcholinesterase Activity. BioMed Res. Int. 2014, 2014, 1-10.

(43) Misra, S.; Kumar, A.; Ratnasekhar, C.; Sharma, V.; Mudiam, M. K. R.; Ram, K. R. Exposure to endosulfan influences sperm competition in Drosophila melanogaster. Sci. Rep. 2014, 4, 7433.

(44) Shivaramaiah, H.; Kennedy, I. Biodegradation of Endosulfan by a Soil Bacterium. J. Environ. Sci. Health, Part B 2006, 41, 895-905.

(45) Kataoka, R.; Takagi, K.; Sakakibara, F. A new endosulfandegrading fungus, Mortierella species, isolated from a soil contaminated with organochlorine pesticides. J. Pestic. Sci. 2010, 35, 326-332.

(46) (a) Xiong, B.; Zhou, A.; Zheng, G.; Zhang, J.; Xu, W. Photocatalytic degradation of endosulfan in contaminated soil with the elution of surfactants. J. Soils Sediments 2015, 15, 1909-1918. (b) Thomas, J.; Kumar, K. P.; Chitra, K. R. Synthesis of Ag Doped Nano $\mathrm{TiO} 2$ as Efficient Solar Photocatalyst for the Degradation of Endosulfan. Adv. Sci. Lett. 2011, 4, 108-114. (c) Thomas, J.; Chitra, K. R. Mater. Focus 2014, 3, 233-238. (d) Miguel, N.; Ormad, M. P.; Mosteo, R.; Ovelleiro, J. L. Photocatalytic Degradation of Pesticides in Natural Water: Effect of Hydrogen Peroxide. Int. J. Photoenergy 2012, 2012, 371714. (e) Santhanalakshmi, J.; Komalavalli, R.; Venkatesan, P. Photo Catalytic Degradation of Chloropyrifos, Endosulphon, Imidocloprid and Quinolphos by Nano Crystalline $\mathrm{TiO}_{2}$ - a Kinetic Study with $\mathrm{pH}$ and Mass Effects. Nanosci. Nanotechnol. 2012, 2, 8-12. (f) Sivagami, K.; Vikraman, B.; Krishna, R. R.; Swaminathan, T. Chlorpyrifos and Endosulfan degradation studies in an annular slurry photo reactor. Ecotoxicol. Environ. Saf. 2016, 134, 327-331. (g) Tapia-Orozco, N.; Vázquez, R. R. Photoactive $\mathrm{TiO}_{2}$ Films Formation by Drain Coating for Endosulfan Degradation. Int. J. Photoenergy 2013, 2013, 560840. (h) Begum, A.; Gautam, S. K. Application of Photocatalysis for the
Degradation of Endocrine disrupting Chemicals: Endosulphan and Lindane. Indian J. Environ. Prot. 2011, 31, 658-665. (i) Malato, S.; Blanco, J.; Maldonado, M. I.; Fernández-Ibáñez, P.; Campos, A. Optimising solar photocatalytic mineralisation of pesticides by adding inorganic oxidising species; application to the recycling of pesticide containers. Appl. Catal., B 2000, 28, 163-174.

(47) http://srdata.nist.gov/ (last accessed on Nov 2016). 